This article was downloaded by: [Fabio Clementi]

On: 10 October 2013, At: 07:55

Publisher: Routledge

Informa Ltd Registered in England and Wales Registered Number: 1072954 Registered

office: Mortimer House, 37-41 Mortimer Street, London W1T 3J H, UK

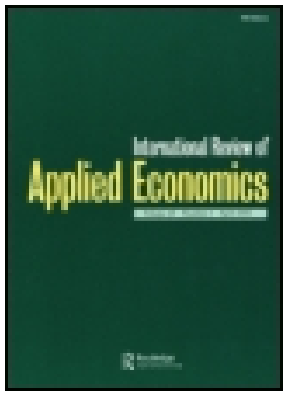

\title{
International Review of Applied Economics
}

Publication details, including instructions for authors and subscription information:

http:// www.tandfonline.com/loi/ cira20

\section{The labour market and the distribution of earnings: an empirical analysis for Italy}

Fabio Clementi ${ }^{\mathrm{a}} \&$ Michele Giammatteo ${ }^{\mathrm{b}}$

a University of Macerata, Department of Political Science, Communication and International Relations, Piazza G. Oberdan 3, 62100 Macerata, Italy

${ }^{b}$ Bank of Italy, Via Nazionale 91, 00184 Rome, Italy Published online: 09 Oct 2013.

To cite this article: Fabio Clementi \& Michele Giammatteo, International Review of Applied Economics (2013): The labour market and the distribution of earnings: an empirical analysis for Italy, International Review of Applied Economics, DOI: 10.1080/ 02692171.2013.838544

To link to this article: http:// dx.doi.org/ 10.1080/ 02692171.2013.838544

\section{PLEASE SCROLL DOWN FOR ARTICLE}

Taylor \& Francis makes every effort to ensure the accuracy of all the information (the "Content") contained in the publications on our platform. However, Taylor \& Francis, our agents, and our licensors make no representations or warranties whatsoever as to the accuracy, completeness, or suitability for any purpose of the Content. Any opinions and views expressed in this publication are the opinions and views of the authors, and are not the views of or endorsed by Taylor \& Francis. The accuracy of the Content should not be relied upon and should be independently verified with primary sources of information. Taylor and Francis shall not be liable for any losses, actions, claims, proceedings, demands, costs, expenses, damages, and other liabilities whatsoever or howsoever caused arising directly or indirectly in connection with, in relation to or arising out of the use of the Content.

This article may be used for research, teaching, and private study purposes. Any substantial or systematic reproduction, redistribution, reselling, loan, sub-licensing, systematic supply, or distribution in any form to anyone is expressly forbidden. Terms \& 
Conditions of access and use can be found at http://www.tandfonline.com/page/termsand-conditions 


\title{
The labour market and the distribution of earnings: an empirical analysis for Italy
}

\author{
Fabio Clementi $^{\mathrm{a} *}$ and Michele Giammatteo ${ }^{\mathrm{b}}$ \\ ${ }^{a}$ University of Macerata, Department of Political Science, Communication and International \\ Relations, Piazza G. Oberdan 3, 62100 Macerata, Italy; ${ }^{b}$ Bank of Italy, Via Nazionale 91, \\ 00184 Rome, Italy
}

(Received 7 April 2012; final version received 12 August 2013)

\begin{abstract}
Using four waves of data from the Participation Labour Unemployment Survey, a database of information on the Italian labour market supply, we address the question of earnings dispersion by applying a 'nested' decomposition procedure of the Theil inequality measure, which combines into a unified framework the standard decompositions by population subgroups and income sources. The empirical evidence obtained points to the key role played by the self-employees in shaping labour income inequality, especially at the upper extreme of the earnings distribution, and the emergence of non-standard forms of employment as an important feature of the contemporary workplace.
\end{abstract}

Keywords: labour income; size distribution; inequality

JEL Classifications: D33, D63

\section{Introduction}

Since the mid-1990s, and at least up to the onset of the current economic crisis, labour market outcomes improved substantially in Italy. Between 1995 and 2007, the most recent year unaffected by the crisis, about 2.5 million jobs were created (mostly in dependent employment) and almost 3 million people entered the workforce (Checchi 2014). Spurred by the positive developments in employment and labour force participation, the unemployment rate declined to around $6 \%$ in 2007 , about half its 1995 peak of over 12\% (Schindler 2009). ${ }^{1}$ However, such improvements were accompanied by poor productivity growth (Lucidi 2007; Codogno 2009; Lucidi and Kleinknecht 2010) and a structural deterioration of Italy's competitiveness (Barca 2005; Faini and Sapir 2009; Codogno 2009). In particular, starting by the end of the 1990s, growth in labour productivity has been modest, even negative in some years, and as a result its level has recently come to be low compared to that prevailing in the early 1990 s and other industrialised countries. ${ }^{2}$ At the same time, the growth of jobs coincided with a modest real wage growth - a yearly increase of 0.7\% during 1996-2007 (Checchi 2014).

The trends outlined above coincided with a period of intense reforms entered by the Italian labour market. Key among them were the reform of the bargaining system of the early 1990s - which introduced the collective bargaining framework still in

*Corresponding author. Email: fabio.clementi@unimc.it 
use - and several labour market reforms aimed to increase the employment rate by means of expansion in labour market flexibility.

The collective bargaining structure laid out in 1993 closed the period of automatic wage indexation (the so-called Scala mobile) which dated back to the mid-1970s. The new bargaining arrangements consist of a national-sectoral bargaining level and a second one decentralised at regional or firm level. At the central (national) level, firms and trade unions define general employment conditions and act for preservation of the purchasing power of real wages with periodic inflation compensations. At the local level, firm and unions negotiate possible rents redistribution on the basis of productivity performances with the objective of enhancing wage flexibility. However, second-level agreements are optional and cannot define wages lower than the sectoral minimum. This has limited to some extent the use of decentralised bargaining, especially among small firms characterised by a low degree of trade unionisation. As a result, annual wage distributions have appeared more compressed than was expected (see for example Casadio 2003, Checchi and Pagani 2005, and Dell Aringa and Pagani 2007). ${ }^{3}$

With regards to the pursuit of labour market efficiency, starting from the end of the 1990s some legislative measures have been specifically directed at fostering flexibility through an increase of the so-called 'atypical' or 'non-standard' forms of employment. More specifically, the measures introduced by the Law 196/1997 (Legge Treu, named after then Labour Minister Tiziano Treu) amplified flexibility by extending the set of temporary contracts and providing incentives for part-time work. The Law 30/2003 (Legge Biagi, named after the advisor on labour market reforms under the 2001-2006 Berlusconi government) further deregulated the use of temporary agency work ${ }^{4}$ and introduced new forms of atypical work such as on-call jobs, job sharing and occasional work. Moreover, the latter reform has given a great thrust to the extensive use of collaboration workers - namely, holders of continuous and coordinated collaboration contracts (Collaborazioni coordinate e continuative, or Co.co.co) and contracts linked to a specific project (Collaborazioni continuative a progetto, or Co.co.pro) - who, although formally self-employed, often work as if they were normal employees. ${ }^{5}$ The large adoption (abuse) of such labour relationships benefited of their more profitable compulsory pension contributions with respect to both standard and fixed-term employment. Furthermore, if on one hand collaboration works allow employers to save labour costs, on the other hand, being a real Italian peculiarity, their inclusion in the category of temporary employment makes the incidence of atypical workers substantially higher in the Italian labour market than in other European countries (Ballarino et al. 2013).

The changes in institutional framework embraced by the Italian labour market during the last two decades certainly contributed to the growth in aggregate employment. However, the crisis has shown that this employment growth has been just a transitional 'honeymoon', growthless job creating effect (Boeri and Garibaldi 2007): since most of the new positions created were temporary and part-time works, almost 800,000 jobs disappeared in the 2009 crisis (Checchi 2014). Indeed, the number of workers in temporary work arrangements more than doubled between 1995 and 2007 , and part-time employment increased by $65 \%$ during that time; permanent and full-time jobs, instead, grew respectively by only $7 \%$ and $9 \%$ over the same years (Schindler 2009). ${ }^{6}$ Furthermore, the employment gains since 1995 occurred at the expense of real wage growth: in fact, a phase of relevant wage moderation took place since the change of the contractual arrangements, causing real wages to 
increase on average less than labour productivity and leading to a decline of the labour share on national income (Tronti 2007; Pugliese 2008). ${ }^{7}$ Several authors have also demonstrated how the prolonged period of wage moderation and the increased flexibility translated into small labour productivity growth, as the reduction of firms' wage bill makes worthwhile the preservation of low-productive jobs and labourintensive productive processes, thereby reducing the incentives for firms to innovate and their scope for training activities and high quality human resource management practices (e.g. Lucidi 2007; but see also Stirati 2008, Lucidi and Kleinknecht 2010, Cappellari et al. 2012, and Cutuli and Guetto 2013).

Under a distributional perspective, while paying out in terms of employment growth, the increased labour market - mainly achieved through a series of reforms 'at the margin' that liberalised the use of temporary contracts but left largely unchanged the legislation applying to permanent workers - has led to a strong segmentation of the Italian labour market, where highly protected and well-paid permanent jobs coexist along with risky and low-paid temporary occupations (Barbieri and Scherer 2009). ${ }^{8}$ This has exacerbated existing earnings inequalities between standard and non-standard forms of employment: ${ }^{9}$ recent econometric studies have indeed shown the existence of a wage differential between temporary and regular employees that has been estimated to range between $7 \%$ and $25 \%$ (Picchio 2006; Cutuli 2008; Lucidi and Raitano 2009a,b; OECD 2012).

Another major factor of inequality in the Italian labour market is related to workers' condition as employees and self-employed: Italy's self-employment rate stands out among the industrialised countries (Barbieri and Bison 2004) and the role of self-employment income in explaining the recent Italian inequality trend has been documented by several studies (see, among others, Torrini 2005, 2006, Quintano et al. 2006, Rani 2008, Fiorio 2011, and Ballarino et al. 2013). Moreover, the Italian distribution of labour earnings showed a persistent increasing pattern in top income shares since the mid-1980s, mainly driven by top wages and self-employment income (Alvaredo and Pisano 2010). Recently, the OECD (2011, p. 3) stated that in Italy 'changes in self-employment income were important drivers of increased earnings inequality: their share in total earned income has increased by $10 \%$ since the mid-1980s, and self-employment income seems more predominant among high earners, to the contrary of many other OECD countries'.

Drawing from these recent labour market developments, in the present work we provide new empirical evidence on the distribution of earnings in Italy, focusing in particular on the inequality consequences of the Italian employment composition as dominated by a large share of self-employment and recently affected by labour market flexibility reforms. In order to avoid using partial measures that only focus on limited parts of the overall distribution, or average wage differentials arising between specific subpopulations, we apply a 'nested' decomposition of the Theil inequality index by population subgroups and income sources, which allows us to investigate how much of the dispersion in earnings concentrated in different parts of the distribution might be accounted for by alternative sources of labour income (standard, self-employment and atypical). There are indeed many reasons to explore inequality in different parts of the distribution. For example, the same degree of inequality can lead to different economic outcomes, depending on whether the inequality is more pronounced in the lower tail of the distribution or in the top end (Morris et al. 1994; Voitchovsky 2005). Additionally, using wage differentials 'at 
the mean' would not accurately reflect the differences across complete earnings distribution (e.g. Van Kerm 2013).

The analysis is conducted with the data of the Participation Labour Unemployment Survey (PLUS), a sample survey on the Italian labour market supply carried out by ISFOL for the years 2005, 2006, 2008 and 2010. ${ }^{10}$ Despite its limited time span, this dataset may be useful to pin down the role that alternative sources of labour earnings play as determinants of income distribution and inequality among workers, particularly for the special emphasis given to the investigation of atypical contracts.

The rest of the work goes on as follows: Section 2 describes the data and methodology adopted for the analysis; Section 3 details the results and findings; Section 4 concludes and draws some policy implications.

\section{Data and methodology}

The PLUS survey consists of four waves of data conducted in 2005, 2006, 2008 and 2010 on around 38,000 individuals - of which 16,000 were workers of both public and private sectors - belonging to the Italian population aged $18-64 .{ }^{11}$ Complementary to other key national statistical sources, ${ }^{12}$ the core objective of PLUS is that of providing reliable estimates of rare and only marginally explored labour market issues. In particular, it is devoted to the study of the distribution of contract types (employee/self-employed status and their articulated subclassifications), job search activity, young and women employment participation, old-age activity and retirement choice, pattern of education and other training, intergenerational dynamics, etc. Some of the key prerogatives of the PLUS survey that seem worthwhile are highlighted here are as follows:

(i) it is planned with the chief purpose of providing accurate estimates of very small-scale phenomena, in that it allows us to produce consistent evaluations of population aggregates of about 100,000 individuals with a coefficient of variation lower than $10 \%$ (for example, the contract type composition of Italian total employment is annually estimated at a degree of desegregation that allows reliable analyses of fixed-term/atypical job distribution) ${ }^{13}$

(ii) consistent labour income variables are derived through the implementation of appropriate techniques in the questionnaire design (e.g. with differentiation of the interview submission process by type of worker), consolidation of respondents' loyalty (for panel units), and thorough data processing (multiple data check and imputation);

(iii) only survey respondents are included (absence of proxy interviews), reducing in this way the extent of measurement errors and partial nonresponses.

The variable chosen for the analysis is the monthly 'gross income' normalised on annual basis ${ }^{14}$ earned by workers classified according to the following categories: standard employees, self-employed and atypical workers. The first category is made up of standard dependent workers with open-ended contracts, which we consider as the traditional dependent employment relationship. The self-employed group, in turn, consists of standard autonomous occupations, such as entrepreneurs, 
cooperative partners, artisans, farmers and other independent jobs (lawyers, doctors and further professional people). Finally, the atypical category brings together nonstandard works of both dependent and autonomous employment relationships, including, among others, ${ }^{15}$ the 'continuous and coordinated contractual relationship'. The latter form of employment relationship, formally autonomous for the Italian labour legislation, covers both genuine independent workers and - more frequently - false independent (or 'economically dependent') workers. Although the PLUS survey allows us to establish the subordination level of labour positions that are midway between dependent and self-employed workers, ${ }^{16}$ we deem to be significant the divergence of atypical jobs from traditional employment relationships.

As we have said, the main objective of this paper is to determine how much of the dispersion in earnings concentrated in different parts of the distribution may be accounted for by alternative sources of labour income. For this purpose, we shall distinguish in the following between two groups of high- and low-income earners, or 'rich' and 'non-rich'. Such groups may be defined in a number of different ways, ${ }^{17}$ but as noted by (Atkinson 2006) all of the definitions used in the existing literature are affected by arbitrariness, and many of them miss the possibility that the 'rich' and 'non-rich' groups are changing proportions of the population. Therefore, in order to limit the subjectivity in definition we follow the method proposed by Inhaber and Carroll (1992; but see also Cowell 2011 for a similar approach) who, based on changes in the shape of the income distribution curve, define the 'rich' as those found on the part of the curve whose shape is similar to the classical Pareto $(1895,1896,1897 \mathrm{a}, \mathrm{b})$ model, which is usually considered as a good approximation of the upper tail of the income distribution. ${ }^{18}$ The threshold dividing 'rich' from 'non-rich' is given in this case by the minimum possible income found in the distribution function

$$
F(x)=1-\left(\frac{x}{x_{\min }}\right)^{-\alpha}, \quad x_{\min } \leq x<\infty, \quad x_{\min }, \alpha>0
$$

which we estimate from the data by adopting a numerical technique proposed by Clauset et al. $(2007,2009)$ based on minimizing the 'distance' between the statistical model (1) and the empirical data. The fundamental idea behind this technique is simple: we choose the estimate of the lowest income $x_{\min }$ that makes the probability distributions of the measured data and the best-fit Pareto model as similar as possible above $\hat{x}_{\min }$. Specifically, for each possible $x_{\min }$ we first obtain the estimate of the shape parameter $\alpha$ over the data $x \geq x_{\min }$ by using the conditional maximum likelihood estimator introduced by Hill (1975)

$$
\hat{\alpha}_{\mathrm{H}}=\left[\frac{1}{m} \sum_{i=1}^{m-1}\left(\ln x_{n-i+1}-\ln x_{n-m+1}\right)\right]^{-1}
$$

where $m=n-k+1$ is the number of extreme sample values above the threshold, $n$ is the sample size and $k$ is the rank of the order statistic $x_{n-m+1}$, and then we compute the Kolmogorov-Smirnov (K-S) goodness-of-fit statistic

$$
D=\max _{x} \geq x_{\min } \mid \hat{F}(x)-F\left(x ; x_{\min }, \hat{\alpha}_{\mathrm{H}}\right)
$$

between the empirical cumulative distribution of the data points being fit, $\hat{F}(x)$, and the theoretical Pareto cumulative distribution function with parameters $x_{\min }$ and $\hat{\alpha}_{\mathrm{H}}$, 
i.e. $F\left(x ; x_{\min }, \hat{\alpha}_{\mathrm{H}}\right)$. Our optimal estimate of the lowest income, $\hat{x}_{\min }^{*}$, is then the value of $x_{\min }$ where $D$ attains its minimum, from which we infer the optimal sample fraction, $m^{*}$, and the optimal estimate of the shape parameter, $\hat{\alpha}_{\mathrm{H}}^{*}$.

Once the parameters have been estimated, by exploiting the asymptotic distribution theory of the Hill estimator (2) we calculate the standard error of the shape parameter as $\frac{\hat{\alpha}_{\mathrm{H}}^{*}}{\sqrt{m}^{*}}$ (e.g. Lux 1996), whereas the uncertainty in the estimate for $x_{\min }$ is derived by making use of a nonparametric bootstrap method (Efron and Tibshirani 1993). That is, given our $n$ income measurements, we generate a synthetic dataset by drawing a new sequence of points $x_{i}, i=1, \ldots, n$, uniformly at random from the original data. Using the method described above, we then estimate $x_{\min }$ for this surrogate dataset. By taking the standard deviation of all the estimates over a large number of repetitions of this process, ${ }^{19}$ we can quantify our uncertainty in the original estimated parameter.

Finally, we also perform a K-S goodness-of-fit test of the Pareto distribution for the observations above $\hat{x}_{\min }^{*}$ by generating a $p$-value that quantifies the plausibility of the hypothesised model. ${ }^{20}$ In detail, our procedure is as follows. First, we fit our empirical data to the Pareto model using the method described above and calculate the K-S statistic (3) for this fit. Next, we generate a large number of synthetic datasets having $m^{*}$ observations randomly drawn from a Pareto distribution with shape parameter $\alpha$ and lower bound $x_{\min }$ equal to those of the distribution that best fits the observed data. We fit each synthetic dataset individually to the Pareto distribution and calculate the K-S statistic for each one relative to its own model. ${ }^{21}$ Then we simply count what fraction of the time the resulting statistic is larger than the value for the empirical data. This fraction is the $p$-value for the fit, and can be interpreted in the standard way: if it is larger than the chosen significance level, then the difference between the empirical data and the model can be attributed to statistical fluctuations alone; if it is smaller, the model is not a plausible fit to the data.

With regard to the inequality analysis, the methodology we shall follow is based on a nested procedure of decomposition of the Theil (1967) index that combines into a simultaneous approach the standard decompositions by population subgroups (which separates total inequality in within- and between-group components) and income sources (which divides overall inequality into proportional factor contributions).

Despite the Gini-based multi-decomposition of inequality proposed by Mussard (2004, 2006), the choice of the Theil index as the reference measure of inequality is motivated by two main reasons: (i) it allows perfect (subgroups) decomposability ${ }^{22}$ and (ii) satisfies the fundamental property of uniform addition for source-based decomposition. ${ }^{23}$ A third, not trivial, advantage is given by its simple and very 'smart' structure. More precisely, it is derivable as a linear function of three basic elements: (pseudo-)Theil subindices of inequality (for groups and income sources), population shares and income shares. In other words, it allows to separate 'size' and 'spread' determinants of inequality both at the subgroup and income source level through the explicit reference to aggregates with economic relevance.

As shown in Appendix A, we can enclose into a unified framework the standard subpopulation and income source decompositions by deriving the following (weighted) bidimensional formulation of the Theil index 


$$
\begin{aligned}
T(Y) & =\sum_{m=1}^{M}\left[\sum_{k=1}^{K} P_{k} \frac{\mu_{k(w)}^{m}}{\mu_{(w)}} \ln \frac{\mu_{k(w)}}{\mu_{(w)}}\right]+\sum_{m=1}^{M}\left\{\sum_{k=1}^{K} P_{k} \frac{\mu_{k(w)}}{\mu_{(w)}}\left[\sum_{i=1}^{n k} p_{i} \frac{y_{i k}^{m}}{\mu_{k(w)}} \ln \frac{y_{i k}}{\mu_{k(w)}}\right]\right\} \\
& =\sum_{m=1}^{M} T b_{w}(m)+\sum_{m=1}^{M} T w_{w}(m)=T b_{w}+T w_{w}
\end{aligned}
$$

where $p_{i}$ represents the individual weight, ${ }^{24} P_{k}$ is the sum of the sample weights $p_{i}$ $\left(i=1, \ldots, n_{k}\right)$ for group $k$, while $\mu_{(w)}, \mu_{k(w)}$ and $\mu_{k(w)}^{m}$ are, respectively, the weighted means for the total, $k$ th subgroup and $m$ th source of the $k$ th subgroup distributions. ${ }^{25}$ Expression (4) implicitly defines the pseudo-Theil of the $Y^{m}$ distribution, $T_{w}(m)=T b_{w}(m)+T w_{w}(m)$, i.e. the absolute contribution to total inequality of the component $m$. It is important to observe that $T_{w}(m)$ does not measure the $m$ source inequality, ${ }^{26}$ as incomes in total and partial distributions have different ranks and the weights are those corresponding to the total distribution. Note also that while the global index $T(Y)$ is always positive, the generic absolute contribution $T_{w}(m)$ can assume both positive and negative values. Hereafter, we shall use the expression of inequality increasing (decreasing) source for the income component showing a positive (negative) value of $T_{w}(m)$. Similarly, we can define $T b_{w}(m)$ as the generic $m$ source contribution to between-group inequality ('between-group pseudo-Thei') and $T w_{w}(m)$ as the $m$ source contribution to within-group inequality ('within-group pseudo-Theil').

The bidimensional decomposition (4) provides a wider set of possible inequality determinants than those that would be obtained by applying separate decompositions. In particular, we are able to distinguish among positive and negative subeffects on within- and between-group inequality components independently on the sign of the overall source contributions. More precisely:

(i) standard subgroup decomposition provides aggregated within and between components of total inequality declining any information on additional source-based determinants;

(ii) simple income source decompositions fail to distinguish in which way income subcomponents affect total inequality through (equalising or not equalising) effects within subpopulations or between them.

The nested approach enforces both the subpopulation and income source decompositions, also representing a useful instrument for the analysis of the inequality consequences of specific government policies (transfers or tax programmes, labour market reforms, etc) ${ }^{27}$

\section{Empirical results}

Using the data and methods described earlier, in this section we fit the classical Pareto model (1) to the upper tail of the Italian labour income distributions and analyse the extent to which the level of inequality within and between the two groups that we consider, respectively, as the 'rich' and the 'non-rich' is affected by earnings accruing from different sources.

The summary statistics in Table 1 suggest that the Pareto distributional assumption may be appropriate in our case. Indeed, there are two noticeable 
Table 1. Sample statistics.

\begin{tabular}{lrrrr}
\hline & \multicolumn{3}{c}{ Wave } \\
\cline { 2 - 5 } & \multicolumn{1}{c}{2005} & \multicolumn{1}{c}{2006} & \multicolumn{1}{c}{2008} & \multicolumn{1}{c}{2010} \\
\hline Obs & 15,868 & 16,475 & 15,299 & 16,587 \\
Pop. ('000) & 21,570 & 22,619 & 22,970 & 22,434 \\
Min & 472 & 231 & 293 & 286 \\
p25 & 11,802 & 11,094 & 11,131 & 10,876 \\
Med. & 14,612 & 14,458 & 15,042 & 14,698 \\
p75 & 18,597 & 18,574 & 18,953 & 18,519 \\
Max & 236,035 & 288,906 & 392,284 & 383,305 \\
Mean & 17,967 & 17,182 & 17,403 & 17,126 \\
St. dev. & 16,786 & 15,195 & 18,732 & 18,869 \\
Skewness & 5.97 & 6.87 & 9.10 & 10.47 \\
& $(<5 \mathrm{e}-05)^{\dagger}$ & $(<5 \mathrm{e}-05)^{\dagger}$ & $(<5 \mathrm{e}-05)^{\dagger}$ & $(<5 \mathrm{e}-05)^{\dagger}$ \\
Kurtosis $^{\mathrm{b}}$ & 55.87 & 82.81 & 121.91 & 160.36 \\
& $(<5 \mathrm{e}-05)^{\dagger}$ & $(<5 \mathrm{e}-05)^{\dagger}$ & $(<5 \mathrm{e}-05)^{\dagger}$ & $(<5 \mathrm{e}-05)^{\dagger}$ \\
\hline
\end{tabular}

Source: authors' own calculations using the PLUS data.

${ }^{a}$ Numbers in round brackets: $p$-values for the D'Agostino (1970) skewness test; the null hypothesis is $H_{0}$ : normality versus the alternative $H_{1}$ : non-normality due to skewness.

${ }^{b}$ Numbers in round brackets: $p$-values for the Anscombe and Glynn (1983) kurtosis test; the null hypothesis is $H_{0}$ : normality versus the alternative $H_{1}$ : no-nnormality due to excess kurtosis.

'Significant at the $0.1 \%$ level.

features. First, the labour income distribution in any one year displays statistically significant evidence for skewness. This can also be inferred by looking at the difference between median and mean income, the former being consistently lower than the latter in each year. Second, the level of kurtosis is significantly above the normal threshold in any one of the years concerned, hinting to the presence of a thick upper tail.

The Pareto diagrams shown in panel (c) of Figure 1 through 4 reveal the extent of what is suggested by Table 1 . These diagrams are plots of the annual gross income $x$, charted on a logarithmic scale, against the complementary cumulative distribution of individuals with annual gross income greater than or equal to $x$ (also on a $\log$ scale). The distinctive feature of distributions that follow the Pareto model in the upper tail - i.e. the approximate linearity above some lower bound of their complementary cumulative distributions plotted on a double logarithmic scale - is clearly evident when examining these graphs, and we can therefore apply the estimation method discussed in Section 2 to make a stronger case for the Pareto hypothesis.

The results of fitting the Pareto distribution to each of the years of data are summarised in Table 2. As can be seen, the model fit varied slightly across years but was generally excellent. This is demonstrated first by the precision of the parameter estimates. All $t$-ratios were indeed significant at the $0.1 \%$ level and relatively large for example, the smallest $t$-ratio for any estimate of $x_{\min }$ was slightly less than 4 and was typically at least seven times larger for $\alpha$. Excellent goodness of fit is also demonstrated by the complementary cumulative distribution plots shown in panel (c) of Figures 1 to 4, where the Pareto model (solid line) exhibits a remarkable agreement with the data in the upper tail of the distributions, even when the latter gets quite noisy (as, for example, in 2008). Furthermore, a look at the Hill plots displayed in panel (b) of the same figures confirms that this model is a good match to the data, 


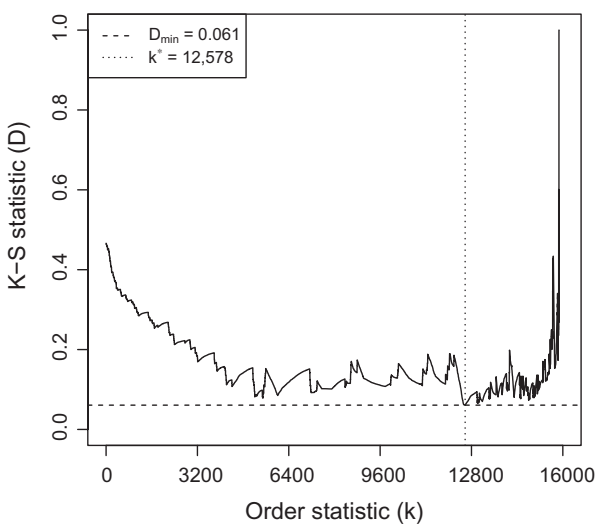

(a) K-S statistic versus rank of ordered sample values

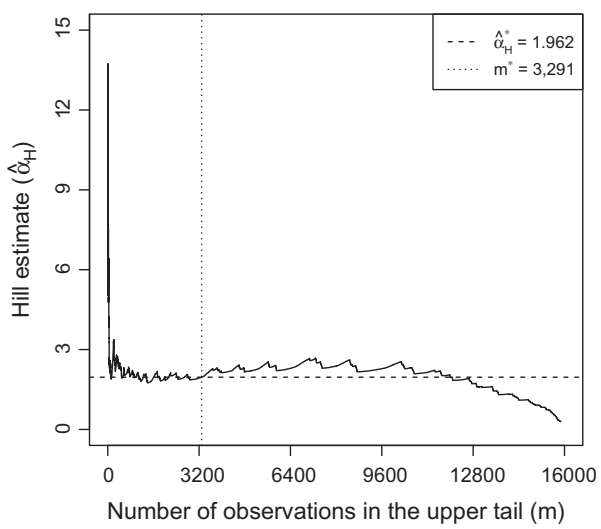

(b) Hill plot

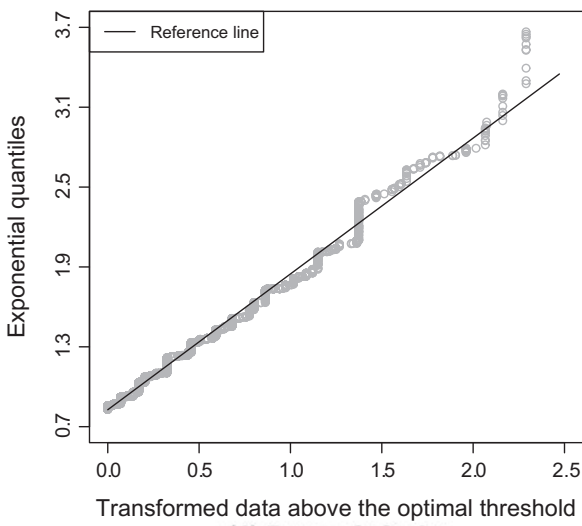

(d) Pareto Q-Q plot

Figure 1. Pareto distribution fit for the PLUS 2005 wave.

Table 2. Parameter estimates and goodness-of-fit test for the Pareto distribution fit. ${ }^{\text {a }}$

\begin{tabular}{ccccc}
\hline Wave & $m^{*}$ & $\hat{x}_{\min }^{*}$ & $\hat{\alpha}_{\mathrm{H}}^{*}$ & $D_{\min }{ }^{\mathrm{b}}$ \\
\hline 2005 & 3,291 & 19,925 & 1.962 & 0.061 \\
& & $(4.673)^{\dagger}$ & $(57.706)^{\dagger}$ & $(0.906)$ \\
2006 & 3,345 & 19,946 & 2.225 & 0.069 \\
& & $(3.898)^{\dagger}$ & $(58.553)^{\dagger}$ & $(0.920)$ \\
2008 & 3,512 & 18,953 & 2.239 & 0.061 \\
& & $(6.407)^{\dagger}$ & $(58.921)^{\dagger}$ & $(0.926)$ \\
2010 & 1,083 & 28,612 & 1.916 & 0.074 \\
& & $(4.453)^{\dagger}$ & $(33.034)^{\dagger}$ & $(0.952)$ \\
\hline
\end{tabular}

Source: authors' own calculations using the PLUS data.

Legend: $m^{*}=$ optimal number of observations in the upper tail to be used for estimation of the shape parameter; $\hat{x}_{\min }^{*}=$ optimal estimate of the lower income limit; $\hat{\alpha}_{\mathrm{H}}^{*}=$ optimal estimate of the shape parameter; $D_{\min }=$ minimum value attained by the K-S statistic.

${ }^{a}$ Numbers in round brackets: $t$-ratios using standard errors estimated by the methods described in Section 2.

${ }^{b}$ Numbers in round brackets: $p$-values computed via 5,000 Monte Carlo replications; the null hypothesis for the test is that the Pareto distribution is a statistically good approximation to the model generating the data.

${ }^{\dagger}$ Significant at the $0.1 \%$ level. 


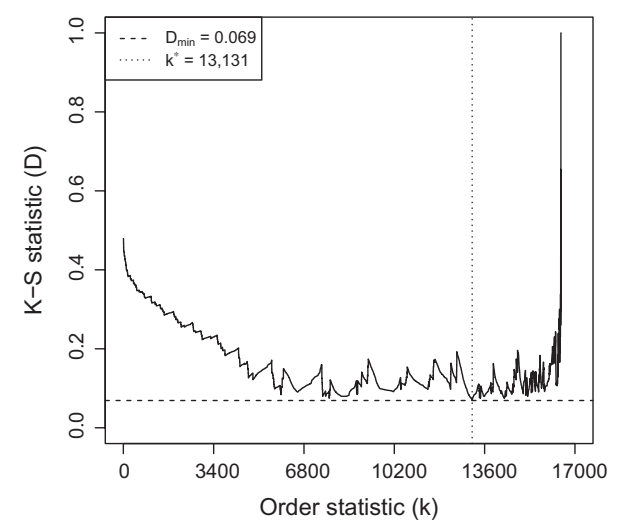

(a) K-S statistic versus rank of ordered sample values

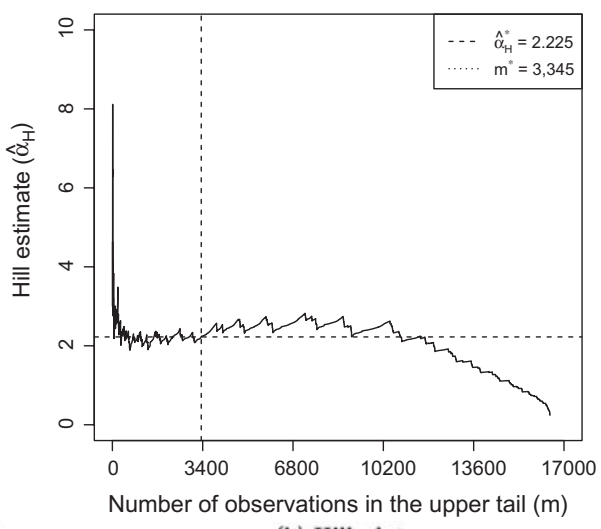

(b) Hill plot

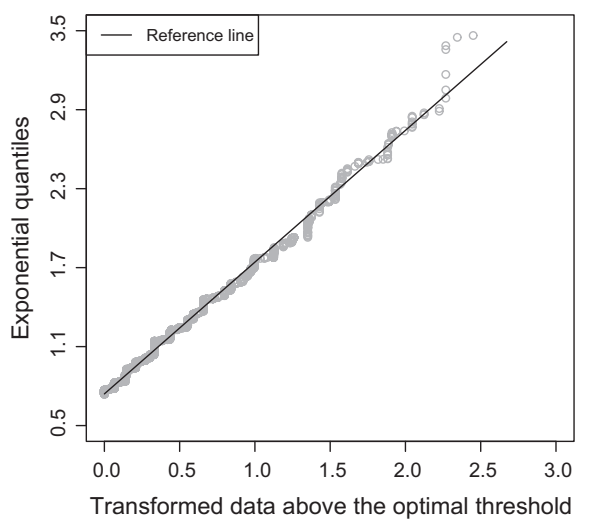

(d) Pareto Q-Q plot

Figure 2. Pareto distribution fit for the PLUS 2006 wave.

since beyond the cut-off income values used the estimates of the shape parameter appear roughly stable. ${ }^{28}$

As a more objective indication of the suitability of the Pareto model, Table 2 reports for each wave the K-S statistic that yields the best fit to the tail data (dashed line in panel (a) of Figures 1-4) and the Monte Carlo $p$-value for the goodness-of-fit test. Notice how all $p$-values are very close to unity, meaning that in all cases our data can be firmly considered to follow the Pareto distribution in the upper tail. This is confirmed by visual inspection of the Pareto Q-Q plots of the sample quantiles above $\hat{x}_{\text {min }}^{*}$, shown in panel (d) of the figures. ${ }^{29}$ As can be seen, every plot lies extremely close to the reference line, and much closer than is typically observed in plots of this type.

It must also be noticed that the size of the group here considered as the 'rich' shrank dramatically in 2010. Indeed, based on the results reported in Table 2, the optimal number of tail observations used in the estimation of the Pareto distribution showed in that year a decline by approximately $70 \%$ with respect to 2008 , while in contrast only few significant changes are detected in the preceding years. This is a probable consequence of the economic crisis started in 2008-2009 in the wake of the global financial crisis, which caused a fall in real mean and median income of 


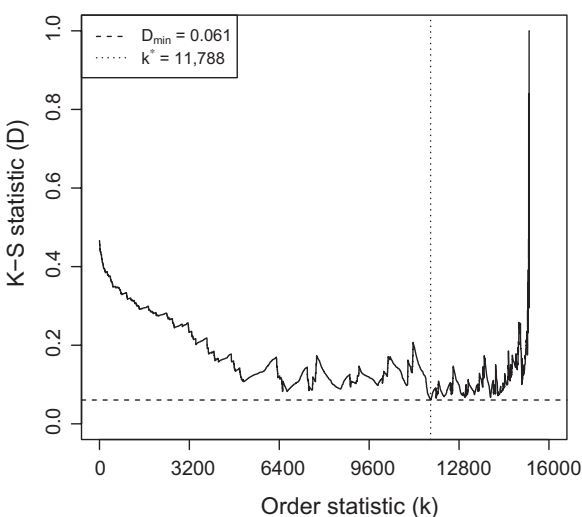

(a) K-S statistic versus rank of ordered sample values

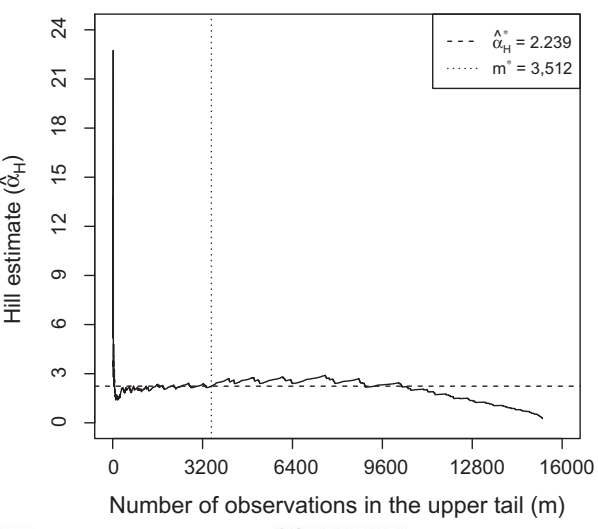

(b) Hill plot

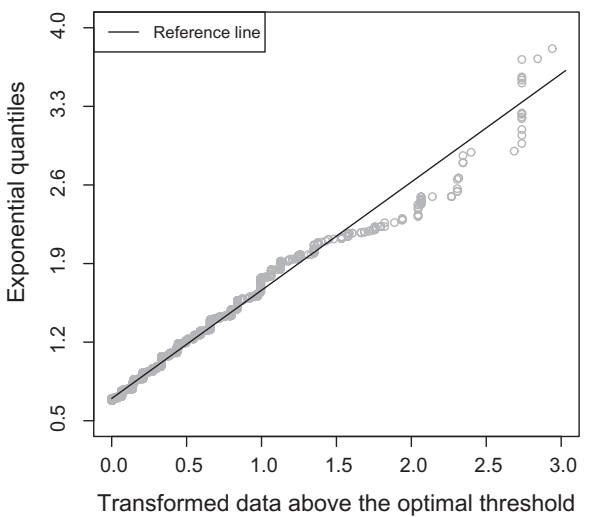

(d) Pareto Q-Q plot

Figure 3. Pareto distribution fit for the PLUS 2008 wave.

about 2\% between 2008 and 2010 (see Table 1). This hypothesis seems also confirmed by the results of a relative distribution analysis, which allows for a decomposition of the relative income density between 2008 and 2010 so as to isolate changes occurring along the entire income range due to differences in the first moment. ${ }^{30}$ Indeed, from inspection of Figure 5 one can see that the mean downshift between 2008 and 2010 impacted the whole range of the income distribution with varying intensity, affecting more negatively the mass of workers above the 2008 median. More specifically, the figure displays a decline of the mass in the upper tail above the 70th percentile and a relatively small increase in the upper-median range of the share of workers between approximately the 65th and the 70th percentile of the 2008 distribution, thus indicating a clear convergence of higher incomes toward the center. ${ }^{31}$

Having provided strong evidence for the presence of a Pareto tail in the Italian labour income distribution, we now turn to assessing earnings inequality through decomposition exercises. The situation is summarised in Tables 3 and 4.

Table 3 contains for each wave of data standard distributional measures, such as population and income shares and relative means. Standard employees represented 


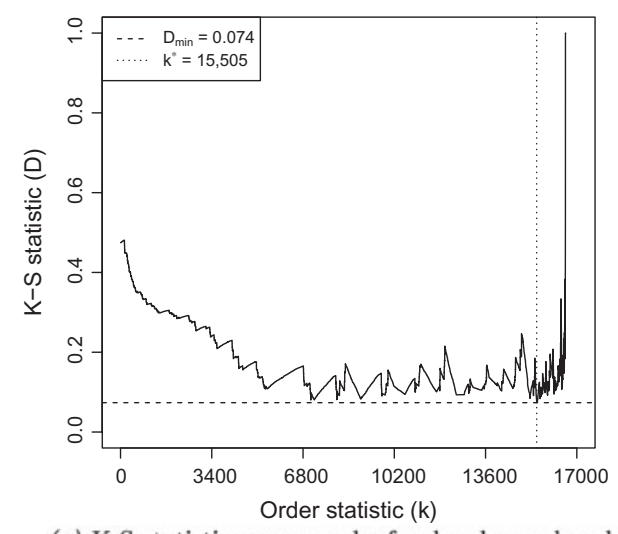

(a) K-S statistic versus rank of ordered sample values

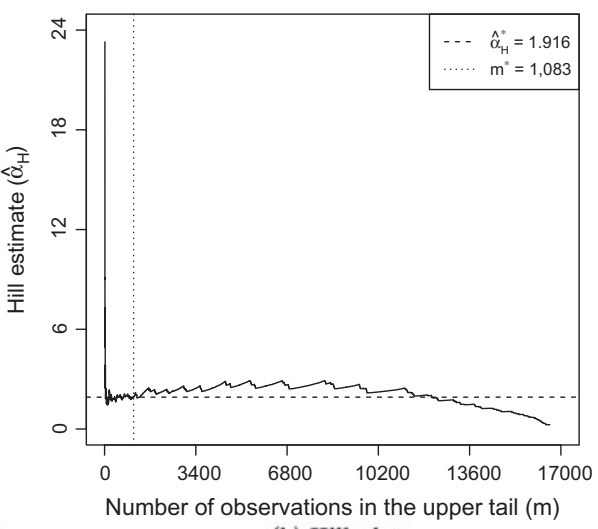

(b) Hill plot

(d) Pareto Q-Q plot

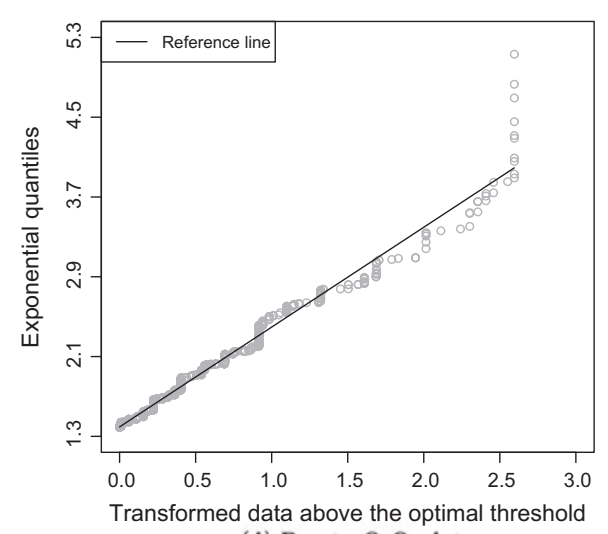

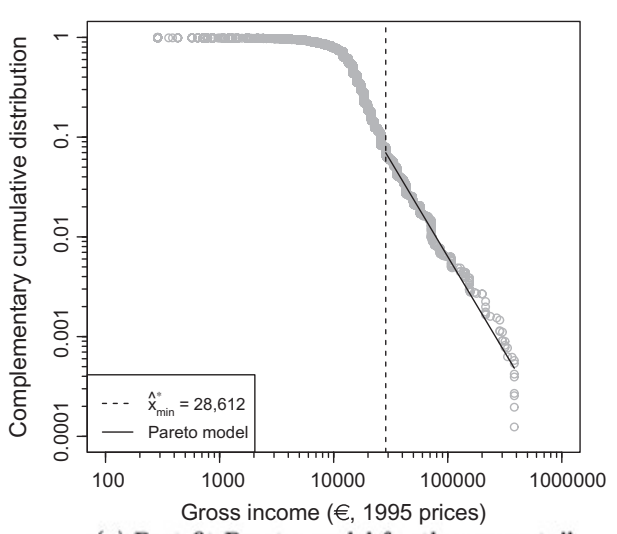

(c) Best-fit Pareto model for the upper tail

Figure 4. Pareto distribution fit for the PLUS 2010 wave.

in each year around $64 \%$ of total population and received on average $61 \%$ of total income. From 2005 to 2010, the self-employed decreased both their population and income shares, while atypical workers followed a reversed trend until 2008. As regards the relative mean, for standard employees it ranges between $90 \%$ in 2005 and $98 \%$ in 2010; for the self-employed the percentage increased from $148 \%$ in 2005 to $155 \%$ in 2008 , whereas in 2010 it decreased to $132 \%$; finally, the mean of atypical workers relative to that of the whole population was around $68 \%$ over the whole period.

By considering the subgroups made up of individuals with income $<\hat{x}_{\min }^{*}$ ("nonrich') and $\geq \hat{x}_{\min }^{*}$ ('rich'), we observe that: (i) the population and income shares of the non-rich decreased between 2005 and 2008 and increased in 2010; (ii) this evidence is reversed for the rich group; (iii) the relative mean income of each group was fairly stable until 2008 (around 70\% for the non-rich and 190\% for the rich) and raised in 2010, notably for the rich.

Table 3 also shows the estimates and corresponding standard errors for both the Theil and Gini measures of inequality. The Theil index for total gross income grew from 0.249 in 2005 to 0.269 in 2010 , save for a temporary decrease in 2006 . The estimated Gini exhibited a similar pattern of change. At the same time, the two 


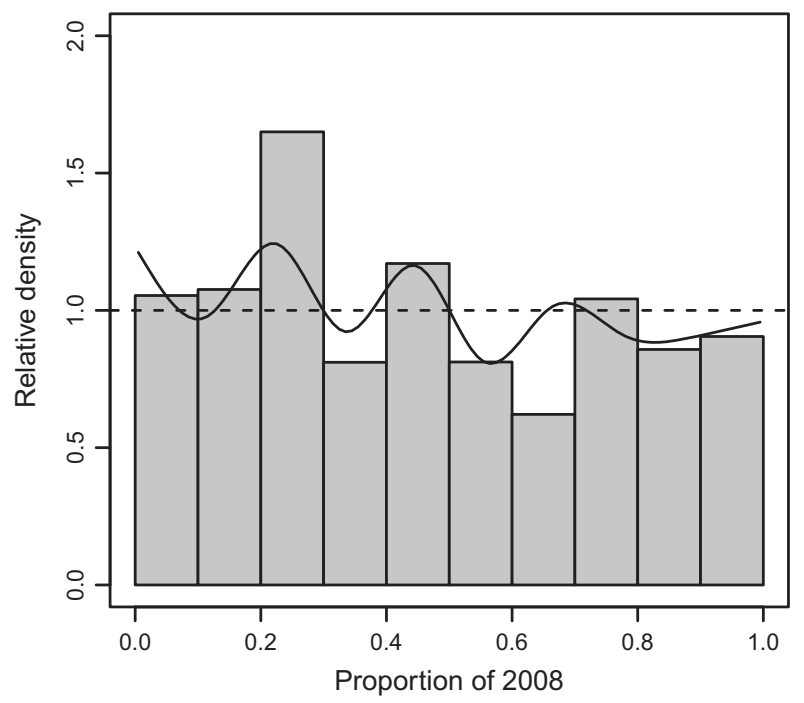

Figure 5. Comparison between 2008 and 2010 Italian labour income distributions: the mean shift effect.

indices reveal sharp inequality heterogeneity both at the population subgroup and income source levels. In particular, self-employed and atypical earning distributions are characterised by high levels of income disparities. However, it is worthwhile to underline that either the ranks and changes of the inequality measured by the two indices are always consistent across the years, thus suggesting the robustness of our findings.

Table 4 presents the results of the standard and 'nested' Theil decomposition by subgroups ('rich' and 'non-rich') and labour income sources (standard, selfemployed and atypical). ${ }^{32}$ For each wave: (i) the rows 'Within' and 'Between' indicate how much of the income source contributions (columns) can be imputed to intra- or inter-groups differences; (ii) the rows labeled 'Non-rich' and 'Rich' specify how the incomes in the lower and upper parts of the annual distributions affect each of the above two components; (iii) the 'Source dec.' row displays the income source contributions resulting from the one-dimensional decomposition rule. Because of the additive property of equation (4), the absolute values sum up both vertically and horizontally; the percent values are calculated with respect to total inequality ('Source dec.') as well as 'Within' and 'Between' components.

The within-group component of labour income inequality increased from more than $49 \%$ in 2005 to around $57 \%$ in 2008 , while it reduced in 2010 . The standard decomposition by income sources highlights the fundamental role played by the selfemployed in shaping total income inequality, even though their relative impact decreased steadily from $112 \%$ to less than $68 \%$. The contribution due to income from standard work was slightly negative in 2005 and positive in the following three waves. In particular, at the end of the observed period it reached a significant value of about $37 \%$. Income stemming from atypical work made marked negative contributions in 2005 and 2006, and weakened in the following two waves. 
Table 3. Summary statistics and inequality measures by population subgroups and income sources. $^{\text {a }}$

\begin{tabular}{|c|c|c|c|c|c|c|}
\hline & Non-rich $^{b}$ & $\operatorname{Rich}^{\mathrm{c}}$ & Standard & Self-employed & Atypical & Gross inc. \\
\hline \multicolumn{7}{|l|}{$2005^{\mathrm{d}}$} \\
\hline Pop. share & $\begin{array}{c}0.772 \\
(0.005)\end{array}$ & $\begin{array}{c}0.228 \\
(0.005)\end{array}$ & $\begin{array}{c}0.648 \\
(0.006)\end{array}$ & $\begin{array}{c}0.223 \\
(0.006)\end{array}$ & $\begin{array}{c}0.129 \\
(0.004)\end{array}$ & $\begin{array}{c}1.000 \\
-\end{array}$ \\
\hline \multirow[t]{2}{*}{ Inc. share } & 0.544 & 0.456 & 0.581 & 0.331 & 0.088 & 1.000 \\
\hline & $(0.010)$ & $(0.010)$ & $(0.010)$ & $(0.011)$ & $(0.004)$ & - \\
\hline \multirow[t]{2}{*}{ Rel. mean } & 0.704 & 1.999 & 0.897 & 1.482 & 0.682 & 1.000 \\
\hline & $(0.009)$ & $(0.028)$ & (0.012) & $(0.036)$ & $(0.016)$ & - \\
\hline Theil & $\begin{array}{c}0.067 \\
(0.002)\end{array}$ & $\begin{array}{c}0.191 \\
(0.017)\end{array}$ & $\begin{array}{c}0.090 \\
(0.005)\end{array}$ & $\begin{array}{c}0.450 \\
(0.025)\end{array}$ & $\begin{array}{c}0.165 \\
(0.012)\end{array}$ & $\begin{array}{c}0.249 \\
(0.014)\end{array}$ \\
\hline Gini & $\begin{array}{c}0.185 \\
(0.003)\end{array}$ & $\begin{array}{c}0.302 \\
(0.011)\end{array}$ & $\begin{array}{c}0.210 \\
(0.004)\end{array}$ & $\begin{array}{c}0.498 \\
(0.012)\end{array}$ & $\begin{array}{c}0.295 \\
(0.010)\end{array}$ & $\begin{array}{c}0.337 \\
(0.007)\end{array}$ \\
\hline \multicolumn{7}{|l|}{$2006^{\mathrm{d}}$} \\
\hline Pop. share & $\begin{array}{c}0.776 \\
(0.006)\end{array}$ & $\begin{array}{c}0.224 \\
(0.006)\end{array}$ & $\begin{array}{c}0.630 \\
(0.007)\end{array}$ & $\begin{array}{c}0.189 \\
(0.006)\end{array}$ & $\begin{array}{c}0.181 \\
(0.005)\end{array}$ & $\begin{array}{c}1.000 \\
-\end{array}$ \\
\hline Inc. share & $\begin{array}{c}0.563 \\
(0.010)\end{array}$ & $\begin{array}{c}0.437 \\
(0.010)\end{array}$ & $\begin{array}{c}0.598 \\
(0.010)\end{array}$ & $\begin{array}{c}0.283 \\
(0.011)\end{array}$ & $\begin{array}{c}0.119 \\
(0.004)\end{array}$ & $\begin{array}{c}1.000 \\
-\end{array}$ \\
\hline Rel. mean & $\begin{array}{c}0.725 \\
(0.009)\end{array}$ & $\begin{array}{c}1.954 \\
(0.029)\end{array}$ & $\begin{array}{c}0.948 \\
(0.012)\end{array}$ & $\begin{array}{c}1.497 \\
(0.043)\end{array}$ & $\begin{array}{c}0.659 \\
(0.014)\end{array}$ & $\begin{array}{c}1.000 \\
-\end{array}$ \\
\hline Theil & $\begin{array}{c}0.067 \\
(0.002)\end{array}$ & $\begin{array}{c}0.172 \\
(0.020)\end{array}$ & $\begin{array}{c}0.090 \\
(0.005)\end{array}$ & $\begin{array}{c}0.414 \\
(0.033)\end{array}$ & $\begin{array}{c}0.173 \\
(0.015)\end{array}$ & $\begin{array}{c}0.225 \\
(0.015)\end{array}$ \\
\hline Gini & $\begin{array}{c}0.190 \\
(0.003)\end{array}$ & $\begin{array}{c}0.278 \\
(0.013)\end{array}$ & $\begin{array}{c}0.211 \\
(0.004)\end{array}$ & $\begin{array}{c}0.477 \\
(0.014)\end{array}$ & $\begin{array}{c}0.305 \\
(0.010)\end{array}$ & $\begin{array}{c}0.323 \\
(0.007)\end{array}$ \\
\hline Pop. share & $\begin{array}{c}0.735 \\
(0.006)\end{array}$ & $\begin{array}{c}0.265 \\
(0.006)\end{array}$ & $\begin{array}{c}0.640 \\
(0.007)\end{array}$ & $\begin{array}{c}0.176 \\
(0.006)\end{array}$ & $\begin{array}{c}0.184 \\
(0.005)\end{array}$ & $\begin{array}{c}1.000 \\
-\end{array}$ \\
\hline Inc. share & $\begin{array}{c}0.509 \\
(0.011)\end{array}$ & $\begin{array}{c}0.491 \\
(0.011)\end{array}$ & $\begin{array}{c}0.602 \\
(0.013)\end{array}$ & $\begin{array}{c}0.272 \\
(0.014)\end{array}$ & $\begin{array}{c}0.126 \\
(0.005)\end{array}$ & $\begin{array}{c}1.000 \\
-\end{array}$ \\
\hline Rel. mean & $\begin{array}{c}0.692 \\
(0.012)\end{array}$ & $\begin{array}{c}1.853 \\
(0.031)\end{array}$ & $\begin{array}{c}0.941 \\
(0.016)\end{array}$ & $\begin{array}{c}1.545 \\
(0.063)\end{array}$ & $\begin{array}{c}0.683 \\
(0.020)\end{array}$ & $\begin{array}{c}1.000 \\
-\end{array}$ \\
\hline Theil & $\begin{array}{c}0.075 \\
(0.003)\end{array}$ & $\begin{array}{c}0.236 \\
(0.027)\end{array}$ & $\begin{array}{c}0.097 \\
(0.007)\end{array}$ & $\begin{array}{c}0.524 \\
(0.044)\end{array}$ & $\begin{array}{c}0.283 \\
(0.050)\end{array}$ & $\begin{array}{c}0.270 \\
(0.021)\end{array}$ \\
\hline Gini & $\begin{array}{c}0.197 \\
(0.003)\end{array}$ & $\begin{array}{c}0.300 \\
(0.017)\end{array}$ & $\begin{array}{c}0.215 \\
(0.004)\end{array}$ & $\begin{array}{c}0.518 \\
(0.019)\end{array}$ & $\begin{array}{c}0.332 \\
(0.017)\end{array}$ & $\begin{array}{c}0.339 \\
(0.010)\end{array}$ \\
\hline Pop. share & $\begin{array}{c}0.920 \\
(0.004)\end{array}$ & $\begin{array}{c}0.080 \\
(0.004)\end{array}$ & $\begin{array}{c}0.655 \\
(0.007)\end{array}$ & $\begin{array}{c}0.182 \\
(0.006)\end{array}$ & $\begin{array}{c}0.163 \\
(0.005)\end{array}$ & $\begin{array}{c}1.000 \\
-\end{array}$ \\
\hline Inc. share & $\begin{array}{c}0.746 \\
(0.013)\end{array}$ & $\begin{array}{c}0.254 \\
(0.013)\end{array}$ & $\begin{array}{c}0.644 \\
(0.011)\end{array}$ & $\begin{array}{c}0.240 \\
(0.011)\end{array}$ & $\begin{array}{c}0.116 \\
(0.005)\end{array}$ & $\begin{array}{c}1.000 \\
-\end{array}$ \\
\hline Rel. mean & $\begin{array}{c}0.810 \\
(0.011)\end{array}$ & $\begin{array}{c}3.187 \\
(0.107)\end{array}$ & $\begin{array}{c}0.983 \\
(0.013)\end{array}$ & $\begin{array}{c}1.320 \\
(0.048)\end{array}$ & $\begin{array}{c}0.711 \\
(0.023)\end{array}$ & $\begin{array}{c}1.000 \\
-\end{array}$ \\
\hline Theil & $\begin{array}{c}0.089 \\
(0.002)\end{array}$ & $\begin{array}{c}0.254 \\
(0.028)\end{array}$ & $\begin{array}{c}0.173 \\
(0.022)\end{array}$ & $\begin{array}{c}0.480 \\
(0.041)\end{array}$ & $\begin{array}{c}0.223 \\
(0.039)\end{array}$ & $\begin{array}{c}0.269 \\
(0.019)\end{array}$ \\
\hline Gini & $\begin{array}{c}0.222 \\
(0.003)\end{array}$ & $\begin{array}{c}0.334 \\
(0.020)\end{array}$ & $\begin{array}{c}0.245 \\
(0.009)\end{array}$ & $\begin{array}{c}0.505 \\
(0.016)\end{array}$ & $\begin{array}{c}0.313 \\
(0.019)\end{array}$ & $\begin{array}{c}0.334 \\
(0.008)\end{array}$ \\
\hline
\end{tabular}

Source: authors' own calculations using the PLUS data.

${ }^{\mathrm{a}}$ Figures might not add up because of rounding.

${ }^{\mathrm{b}}$ Includes individuals with income $<\hat{x}_{\min }^{*}$.

${ }^{c}$ Includes individuals with income $\geq \hat{x}_{\min }^{*}$.

${ }^{\mathrm{d}}$ Numbers in round brackets: estimated standard errors.

The contribution to overall inequality of standard incomes shifted from negative to positive by a change of sign of the between-group component (from around $-10 \%$ in 2005 to approximately $13 \%$ in 2008 ) and, only in 2010 , because of the 
Table 4. Standard and nested decomposition of the Theil index by population subgroups and income sources. ${ }^{\mathrm{a}}$

\begin{tabular}{|c|c|c|c|c|c|c|c|c|c|}
\hline & \multicolumn{4}{|c|}{ Absolute values } & \multicolumn{4}{|c|}{ Percent values } & \multirow{2}{*}{$\begin{array}{c}\text { Subgroup } \\
\text { dec. }\end{array}$} \\
\hline & Standard & $\begin{array}{l}\text { Self- } \\
\text { employed }\end{array}$ & Atypical & $\begin{array}{l}\text { Gross } \\
\text { inc. }\end{array}$ & Standard & $\begin{array}{l}\text { Self- } \\
\text { employed }\end{array}$ & Atypical & $\begin{array}{l}\text { Gross } \\
\text { inc. }\end{array}$ & \\
\hline \multicolumn{10}{|l|}{2005} \\
\hline Non-rich ${ }^{\mathrm{b}}$ & 0.044 & -0.001 & -0.007 & 0.036 & 35.8 & -0.8 & -5.7 & 29.3 & - \\
\hline $\operatorname{Rich}^{\mathrm{c}}$ & -0.042 & 0.130 & -0.001 & 0.087 & -34.1 & 105.7 & -0.8 & 70.7 & - \\
\hline Within & 0.002 & 0.129 & -0.007 & 0.123 & 1.6 & 104.9 & -5.7 & 100.0 & 49.4 \\
\hline Non-rich ${ }^{\mathrm{b}}$ & -0.140 & -0.026 & -0.024 & -0.190 & -111.1 & -20.6 & -19.0 & -150.8 & - \\
\hline $\operatorname{Rich}^{\mathrm{c}}$ & 0.127 & 0.177 & 0.013 & 0.316 & 100.8 & 140.5 & 10.3 & 250.8 & - \\
\hline Between & -0.013 & 0.150 & -0.012 & 0.126 & -10.3 & 119.0 & -9.5 & 100.0 & 50.6 \\
\hline Source dec. & -0.011 & 0.279 & -0.019 & 0.249 & -4.4 & 112.0 & -7.6 & 100.0 & 100.0 \\
\hline \multicolumn{10}{|l|}{2006} \\
\hline Non-rich ${ }^{\mathrm{b}}$ & 0.048 & 0.001 & -0.011 & 0.038 & 42.5 & 0.9 & -9.7 & 33.6 & - \\
\hline $\operatorname{Rich}^{\mathrm{c}}$ & -0.037 & 0.112 & 0.000 & 0.075 & -32.7 & 99.1 & 0.0 & 66.4 & - \\
\hline Within & 0.011 & 0.112 & -0.011 & 0.113 & 9.7 & 99.1 & -9.7 & 100.0 & 50.2 \\
\hline Non-rich ${ }^{\mathrm{b}}$ & -0.126 & -0.023 & -0.032 & -0.181 & -112.5 & -20.5 & -28.6 & -161.6 & - \\
\hline $\operatorname{Rich}^{\mathrm{c}}$ & 0.137 & 0.142 & 0.013 & 0.293 & 122.3 & 126.8 & 11.6 & 261.6 & - \\
\hline Between & 0.011 & 0.119 & -0.018 & 0.112 & 9.8 & 106.3 & -16.1 & 100.0 & 49.8 \\
\hline Source dec. & 0.022 & 0.232 & -0.029 & 0.225 & 9.8 & 103.1 & -12.9 & 100.0 & 100.0 \\
\hline \multicolumn{10}{|l|}{2008} \\
\hline Non-rich ${ }^{\mathrm{b}}$ & 0.050 & -0.002 & -0.010 & 0.038 & 32.5 & -1.3 & -6.5 & 24.7 & - \\
\hline $\operatorname{Rich}^{\mathrm{c}}$ & -0.043 & 0.144 & 0.015 & 0.116 & -27.9 & 93.5 & 9.7 & 75.3 & - \\
\hline Within & 0.007 & 0.142 & 0.005 & 0.154 & 4.5 & 92.2 & 3.2 & 100.0 & 57.0 \\
\hline Non-rich ${ }^{\mathrm{b}}$ & -0.133 & -0.018 & -0.036 & -0.187 & -114.7 & -15.5 & -31.0 & -161.2 & - \\
\hline $\operatorname{Rich}^{\mathrm{c}}$ & 0.148 & 0.137 & 0.018 & 0.303 & 127.6 & 118.1 & 15.5 & 261.2 & - \\
\hline Between & 0.015 & 0.119 & -0.018 & 0.116 & 12.9 & 102.6 & -15.5 & 100.0 & 43.0 \\
\hline Source dec. & 0.022 & 0.261 & -0.012 & 0.270 & 8.1 & 96.7 & -4.4 & 100.0 & 100.0 \\
\hline \multicolumn{10}{|l|}{2010} \\
\hline Non-rich ${ }^{\mathrm{b}}$ & 0.076 & 0.003 & -0.014 & 0.066 & 58.0 & 2.3 & -10.7 & 50.4 & - \\
\hline $\operatorname{Rich}^{c}$ & 0.036 & 0.024 & 0.005 & 0.065 & 27.5 & 18.3 & 3.8 & 49.6 & - \\
\hline Within & 0.112 & 0.027 & -0.008 & 0.131 & 85.5 & 20.6 & -6.1 & 100.0 & 48.7 \\
\hline Non-rich ${ }^{\mathrm{b}}$ & -0.116 & -0.019 & -0.021 & -0.157 & -84.1 & -13.8 & -15.2 & -113.8 & - \\
\hline $\operatorname{Rich}^{c}$ & 0.105 & 0.174 & 0.016 & 0.295 & 76.1 & 126.1 & 11.6 & 213.8 & - \\
\hline Between & -0.012 & 0.155 & -0.005 & 0.138 & -8.7 & 112.3 & -3.6 & 100.0 & 51.3 \\
\hline Source dec. & 0.101 & 0.182 & -0.014 & 0.269 & 37.5 & 67.7 & -5.2 & 100.0 & 100.0 \\
\hline
\end{tabular}

Source: authors' own calculations using the PLUS data.

${ }^{a}$ Figures might not add up because of rounding.

${ }^{\mathrm{b}}$ Includes individuals with income $<\hat{x}_{\min }^{*}$.

${ }^{\mathrm{c}}$ Includes individuals with income $\geq \hat{x}_{\min }^{*}$.

strong increase of the within-group inequality share (about 85\%). Moreover, the nested procedure allows us to impute most of this result to the inequality-increasing contribution (nearly 27\%) arising among the rich standard earners. The selfemployed inequality contribution fell over time mainly because of the decreasing positive effects of the within-group components referred to the rich group. Finally, with regards to the atypical workers we observe a nearly generalised negative contribution, apart from a few but significant exceptions. In particular, the rich incomes accounted for positive between-group contributions over the entire period analysed, whereas for the within-group inequality this is true only starting with the 2008 wave. 


\section{Concluding remarks}

In this paper we have examined the distribution of labour earnings in Italy using four waves of data from the Participation Labour Unemployment Survey (PLUS), a sample survey on the Italian labour market supply. The main results are briefly summarised below.

First, we have found that the shape of the Italian labour income distribution in any one year of the analysis is highly skewed to the right with a 'fat' and long upper tail, a feature pointing to the existence of a relatively small number of very well-paid individuals. This has called into question the use of the traditional Pareto model to properly separate the group of the rich from poorer workers.

Second, in order to shed light on the roots of the labour income inequality, we have carried out a nested decomposition of the Theil inequality measure that emphasised the twofold role played by sources of labour income and their distribution among the groups of rich and non-rich earners. The results highlighted the decisive role played by self-employment income in shaping total inequality through large positive effects coming from high earning receivers. Earnings from standard employment also exhibited positive contributions due to income disparities concentrated in the bulk of the annual distributions. Atypical earnings affected inequality negatively in each year, with limited positive contributions made by the rich group.

We believe that the high level of earnings inequality is not inevitable, and policy choices can contribute to reduce it. ${ }^{33}$ Consistently with country-specific features, labour market policies should jointly take care of the labour income increase and its fair distribution, pursuing at the same time improvements in labour productivity, skill premium, returns on educational investment and employment conditions. Accordingly, our results provide some clear policy indications.

In particular, the following property holds from our decomposition methodology: increasing the income share of a source which contributes negatively (positively) to total inequality would imply, ceteris paribus, an overall equalising (disequalising) effect. ${ }^{34}$ This suggests, for example, that an increase of 'non-standard' earnings would decrease the total level of inequality. As already mentioned before, several empirical studies verified the existence of a significant wage gap between 'standard' and 'non-standard' wages in Italy, mainly due to the adoption of non-standard forms of contracts squarely focused on labour cost reduction rather than other legitimate motivations. ${ }^{35}$ In this context, policies interventions should discourage opportunistic employer's hiring practices. Inequality could decrease as soon as atypical employment relationships would concern genuine professionals, which are expected to earn more than 'economically dependent workers'.

Likewise, an increase of standard earnings among the 'non-rich' would involve less total inequality. This might represent a desirable policy option for less-protected and low-paid employees such as women, immigrants and young workers whose low earnings are not always justified by shorter working hours or lower productivity. ${ }^{36}$ More in general, minimum wage protection policies, purchasing power preservation systems, as well as the adoption of contrast measures for preventing various discrimination and irregular practices could contribute to reducing earnings differences. $^{37}$

Furthermore, the significant self-employed contribution to total labour income inequality suggests supporting a firm's business. In particular, desirable policy decisions could promote easier and timely credit concessions able to enhance 
innovation investments and size development of small firms. The final objective should be the higher profitability of secondary employers lying on the lower side of the earnings distribution, which would certainly contribute to narrow self-employed inequality.

Finally, our analysis seems to highlight preliminary effects on inequality due to the ongoing economic crisis. Between 2008 and 2010, the self-employed accounted for a definitely lower income share, relative mean and earnings dispersion that altogether pushed down the inequality contribution of this source. Such results can be firstly motivated by minor economic opportunities and consequential smaller monetary returns implied by the economic situation. Taken together with the increase of the self-employed population share (see Table 3), this is compatible with employment flows from atypical to self-employment positions. In other words, the negative economic conjuncture may have induced, once more, a substitution of non-standard employees (largely uncovered by labour legislation) with autonomous 'false' positions in order to reduce labour costs. Nonetheless, it is interesting to note that total inequality decreased only by a few points between 2008 and 2010. Our results suggest that this was mainly due to the increasing dispersion of standard earnings, which occurred simultaneously with the slight increases of their income share and relative mean. The reason behind this event should again reside in the segmentation of the Italian productive system, characterised by high performing sectors, which can also sustain employees' earnings during a negative conjuncture, along with others made up of less effective (or ineffective) firms, forced to select among worker firing and severe earning cuts.

\section{Acknowledgements}

We gratefully acknowledge helpful comments from two anonymous referees, which helped to improve this article significantly. We are also grateful to Stéphane Mussard for help with his GAUSS code on the Gini multi-decomposition by population subgroups and income sources. Finally, we acknowledge ISFOL for providing us with data from the PLUS survey. Microdata use authorisation code ISFOL PLUS 2006/428.

The opinions expressed by Michele Giammatteo in this paper are those of the author and do not necessarily reflect those of the Bank of Italy. The usual disclaimer applies.

\section{Notes}

1. Employment growth continued even in 2008, when the current crisis unfolded in the final quarter of the year. However, some traces of it are already visible in the increase of the unemployment rate to about $6.7 \%$ in the same year. Since then, the Italian unemployment rate started to steadily increase to $7.8 \%$ in 2009 and $8.4 \%$ in 2010 and 2011 (Ciccarone and Damioli 2012).

2. For instance, Lucidi (2007) and Lucidi and Kleinknecht (2010) estimate that the average annual increase of labour productivity, which has systematically lagged behind the average of 15 European Union, slowed down from around 1.9\% in the 1992-1996 period to approximately $0.9 \%$ in the years $1996-2000$, and came close to zero in 2000-2004. In addition, as maintained by Codogno (2009), since the mid-1990s - and especially in the early 2000 s - the reduction in the contribution of labour productivity to GDP growth more than offset the positive contribution of labour utilisation, hence resulting in weak overall GDP growth.

3. Traditional wage-setting institutions like collective bargaining affect workers predominantly at the bottom or middle of the wage distribution. By contrast, wage-setting mechanisms of high executives (the 'working rich') concern workers at the very top of the distribution. The importance of executive compensations to explain the 
rise in top income shares during the last quarter of the twentieth century has been a standard result in all the studies analysing income concentration within the top groups in Anglo-Saxon countries. A tentative explanation explored by Piketty and Saez (2003, 2006) but see also Lemieux 2008 and Lemieux et al. 2009) is that the growth in performance-related schemes - which affect the compensation of high executives - and the change in social norms - regarding inequality and the acceptability of very high wages - have removed some implicit barriers to the rise of incomes for the very highest earners. However, the surge experienced by top incomes in continental Europe and other advanced countries such as Japan has been small relative to existing estimates for English-speaking countries, and even the results for Italy are fairly modest (Alvaredo and Pisano 2010).

4. Indeed, a previous law (368/2001) had been introduced with the explicit objective of liberalising significantly the employers' use of temporary contracts - by reducing the need of giving a justification for the use of fixed-term work relationships.

5. Alternatively, employers can outsource tasks to single individuals who are formally independent but actually 'economically dependent' on the firm.

6. Likewise, some structural problems characterising the Italian labour market appeared to be almost unaffected by this 'employment miracle', which was unevenly distributed across sex and regions: unemployment in the South remained in fact very high compared with the Central and Northern regions, and even though the female component reduced its distance from the male counterpart, the women's labour market position remained quite unfavourable, notably in the Southern regions (see for example Checchi 2014).

7. The magnitude of the wage restraint period appears significant also in an international comparison, where Italy ranked bottom among industrialised countries for real wage growth during the decade 1992-2002 (Zenezini 2004).

8. This dualism has also been worsened by: the uneven unemployment insurance schemes in use - wage supplementation funds, such as the Cassa integrazione guadagni, are in fact limited to workers with certain contracts, generally employed in large firms within specific sectors of the industry; the dissimilar occupational prospects they deal with; the low predisposition of the firms to invest in the human capital of atypical workers (Ballarino et al. 2013), especially during negative economic conjunctures (Cutuli and Guetto 2013).

9. See Rani (2008) for an attempt to assess the extent to which changes in employment patterns are associated with the rise in income inequality observed over the past two decades in the majority of countries. As for Italy, see Ballarino et al. (2013).

10. The Italian Institute for the Development of Vocational Training for Workers (ISFOL) is a research institute connected to the Italian Ministry of Labour and Social Affairs and member of the Italian National Statistical System (SISTAN). The PLUS survey is included in the Italian National Statistical Programme (NSP), the SISTAN tool for planning statistical activity of public interest. For a collection of various research results on the Italian labour market conducted by ISFOL using this dataset, see Mandrone and Radicchia $(2005,2012)$. The PLUS data are available at no cost by sending a request email to plus@isfol.it.

11. The age range was 15-64 for the 2005 wave. Furthermore, starting with the 2006 wave, a panel section consisting of a large number of observations (about $65 \%$ ) was additionally provided.

12. In Italy, information on labour market characteristics can be obtained from various sources. Two prominent examples are the Labour Force Survey (LFS, http://www.istat.it/ en/archive/36394), conducted quarterly by the National Institute for Statistics (ISTAT), and the Work Histories Italian Panel (WHIP, http://www.laboratoriorevelli.it/whip/ whip_datahouse.php?lingua=eng), built from a sample of microdata from the administrative archives of the National Institute of Social Security (INPS). However, while the former considers the household as a sampling unit, the latter includes microdata on private sector employees only.

13. See for example Corsetti and Mandrone (2010) and Mandrone and Marocco (2012) for applications related to this issue. 
14. This variable is in current year euros $(€)$ and we use the consumer price index for the whole nation (NIC) based on the year 1995 in order to obtain distributions of 'real' income. The series of the NIC index is publicly available on the ISTAT's website at the address: http://www.istat.it/it/files/2011/02/indici_nazionali_nic tuttilivaggr.xls. Furthermore, because of the complex sampling design of the PLUS survey, data make use throughout the analysis of appropriate sampling weights to produce representative estimates and correct standard errors and statistical tests. The expansion weights coming with the PLUS survey are calibrated using GREG estimation Deville and Sarndal (1992), which guarantees reduction of sample selection bias, small estimation variance and large consistency with the standard labour market indicators derivable from the ISTAT's LFS survey.

15. Other employment relationships that may be included in this category are fixed-term contracts, job on call, job sharing and temping work provided by employment agencies.

16. For instance, the PLUS survey allows us to single out workers economically dependent on a single employer, subject to compulsory daily presence, using employer's equipment and performing the same tasks as some of their fellows. They are contractually treated as 'autonomous' workers, but any specific skills, professional knowledge or specific competencies are not actually needed.

17. The definition closest to the existing literature would specify, usually arbitrarily, a percentage of the total income (like the top $1 \%, 5 \%, 10 \%$ or even $20 \%$ ) and identify the population found above and below this threshold as, respectively, the 'rich' and 'nonrich'. Also, the definition could take an arbitrary number of persons - as in the UK Sunday Times list of richest people, or have a minimum cut-off value in order for a person to qualify as 'rich' - as in the US 'Forbes 400' list. Other alternatives based on the position in the income distribution could use the deviation from the mean (median) income or a multiple of this quantity as a parameter, defining the 'rich' - and, complementarily, the 'non-rich' - as those whose incomes are beyond a determined amount of standard deviation in relation to the average (median) of the distribution, or those who have more than $x$ times the mean (median) income.

18. An extensive historical survey of the use of the Pareto distribution in the context of income and wealth distributions can be found for example in Arnold (1983). For the mathematics of the Pareto distribution see Kleiber and Kotz (2003).

19. In practice, we perform 100 such bootstrap samplings.

20. One of the features of the K-S statistic is that its distribution is known for datasets truly drawn from any given distribution. This allows one to write an explicit expression in the limit of large $n$ for the $p$-value. Unfortunately, this expression is only correct so long as the underlying distribution is fixed (see for example Stephens 1986). If, as in our case, the underlying distribution is itself determined by fitting to the data and hence varies from one dataset to the next, we cannot use this approach, which is why the Monte Carlo procedure described in the main text is instead recommended.

21. Note crucially that for each synthetic dataset we compute the K-S statistic relative to the best-fit Pareto model for that dataset, not relative to the original distribution from which the dataset was drawn. In this way we ensure that we are performing for each synthetic dataset the same calculation that we performed for the real dataset, a crucial requirement if we wish to get an unbiased estimate of the $p$-value (Capasso et al. 2009).

22. See for example Cowell (1980a,b) and Shorrocks (1984).

23. Following Morduch and Sicular (2002), a rule of factor decomposition satisfies the property of uniform addition if it registers strictly negative contributions to overall inequality for any income component equally distributed and positive. In this regard, Podder (1993) claims that it is reasonable to think that the addition of a constant to all incomes leads to a reduction in inequality if we accept relative measures. See also Shorrocks (1982, 1983) and Paul (2004) on this issue.

24. The weights are proportional to the actual population of the strata from which the sample observations are drawn from. In the PLUS survey, strata are defined by region, type of city (metropolitan/not metropolitan), age (five classes), sex and employment status (employed, unemployed, student, retired, other inactive/housewife). A detailed description of the sampling design and strategy of the survey is contained in Giammatteo (2009). 
25. Notice that when the unweighted formulation is adopted we simply have $p_{i}=\frac{1}{n_{k}}$ and

$P_{k}=\frac{n_{k}}{n}$.
26. The $m$ th source inequality is, instead, given by $T_{m}=\frac{1}{n} \sum_{i=1}^{n} \frac{y_{i}^{m}}{\mu_{m}} \ln \frac{y_{i}^{m}}{\mu_{m}}$.

27. Simpler but less precise approaches are given by: (i) analyses of the relation between inequality and public policies through the use of dispersion graphs between inequality indices and country expenditures for social security (see Beblo and Knaus 2001); (ii) pre- and post-transfer inequality computations in order to assign factor contributions as relative difference between the two values (see Keane and Prasad 2002, and Forster et al. 2003). As emphasised by Lerman (1999, p. 341), the latter approach 'can yield misleading results'.

28. The so-called 'Hill plot' is a visual diagnostic tool charting the Hill estimate of the shape parameter $\hat{\alpha}_{H}$ for each $x_{\min }$. The idea is to visually identify a region where the plot levels off, representing a stable estimate of $\alpha$, and then choose $x_{\min }$ as the beginning of that region (see for example Beirlant et al. 2004).

29. Since a log-transformed Pareto random variable is exponentially distributed, the coordinates of the points on a Pareto Q-Q plot follow immediately from the exponential case by taking the transformation $\ln \frac{X}{x_{\min }} \sim \operatorname{Exp}(\alpha)$.

30. For our purposes, the 'relative distribution' is defined as the ratio of the income density in the comparison year (2010) to the income density in the reference year (2008) evaluated at each quantile of the reference distribution, and can be interpreted as the fraction of the comparison population that falls in each quantile of the reference population. This allows us to identify and locate the changes that have occurred in the entire Italian labour income distribution between the two years. In particular, when the fraction of individuals in a quantile is higher (lower) than the fraction in the reference year, the relative distribution will be higher (lower) than 1 . Where there is no change, the relative distribution will be flat at the value 1 . Furthermore, this approach also allows us to decompose the relative density into changes in location and changes in shape, in order to emphasise differences between the comparison and the reference populations that could be attributed to a change in the average (or median) income or to changes of the shape (including differences in variation, skewness and other distributional characteristics). We refer the reader to Handcock and Morris $(1998,1999)$ for a more formal definition of the relative distribution.

31. Alternative indices, such as the median, can be considered. The corresponding results do not differ in a significant way and are not reported here.

32. A similar decomposition exercise using the Gini index is presented for robustness purposes in Appendix B.

33. In general, more policy options are available when the disposable income is the studied variable. This allows taking into consideration the distributional effects of government taxes and transfers and other private incomes (e.g. financial revenues) responsible for economic inequality.

34. For a detailed discussion of this point see Giammatteo (2007).

35. Coordinated and project collaborations should be related to the execution of time-limited objectives or requests for specific qualifications (consultants); fixed-term contracts should be adopted for replacing the temporary absence of an existing employee (e.g. childcare purposes) or for dealing with an evident loss of firm's profitability (after an agreement with local trade unions).

36. See OECD (2012).

37. Some empirical findings provide evidence of the irregular practice of underreporting the number of paid working days, as some firms can reduce hourly wage without violating the minimum requirements (Contini et al. 2008).

38. Each individual only belongs to one group and the overall population is entirely covered by the $K$ groups.

39. Hereafter, we exclude the trivial case of constant distributions, i.e. $Y \neq e_{n} \mu$, where $e_{n}=(1,1, \ldots, 1)$. Moreover, for each of the sub-income distribution $Y^{m}$ the following minimum requirement is always satisfied: $y_{i}^{m} \geq 0$, and $y_{j}^{m}>0$ at least for one $j$.

40. Following Dagum's (1997) Gini decomposition by subgroups, this method yields a gross between-group component, $G_{g b}$, which is different from the standard between-group 
measure (say $G_{b}$ ) in the sense that the former gauges all pairs of income differences between agents across different groups, whereas the latter gives the inequality between the mean incomes of the groups. The gross between-group component is also decomposable as $G_{g b}=G_{b}+G_{t}$, where $G_{t}$ measures the inequalities between the subgroups limited to the overlap between their distributions. Since in our case the subgroup income distributions do not overlap, gross and standard between-group inequalities coincide. Therefore, in the text we shall use the expression 'between-group inequality' without any qualifier.

41. We may note here that this technique is not appropriate to assess the contribution of an income source of a precise subgroup to the between-group inequality. The breakdown of the Gini coefficient is thus not fully accomplished, since it does not entail the estimation of the combinations 'inequality between subgroups / due to source $m$ of subgroup $k^{\prime}$ - which is instead possible by using the nested Theil decomposition method.

42. The estimates of the marginal effects that every income source has on the Gini index of income inequality have been obtained by using the approach proposed by Lerman Yitzhaki (1985).

\section{References}

Alvaredo, F., and E. Pisano. 2010. “Top incomes in Italy, 1974-2004." In Top Incomes. A Global Perspective, edited by A. B. Atkinson and T. Piketty, 625-663. New York: Oxford University Press.

Anscombe, F. J., and W. J. Glynn. 1983. "Distribution of the kurtosis statistic $b_{2}$ for normal statistics." Biometrika 70 (1): 227-234.

Arnold, B. C. 1983. Pareto Distributions. Fairland: International Co-operative Publishing House.

Atkinson, A. B. 2006. “Concentration among the Rich.” Research Paper 2006/151, World Institute for Development Economics Research, United Nations University, New York. Available at: http://www.wider.unu.edu/publications/working-papers/research-papers/ 2006/en_GB/rp2006-151/

Ballarino, G., M. Braga, M. Bratti, D. Checchi, A. Filippin, C. Fiorio, M. Leonardi, E. Meschi, and F. Scervini. 2013. "Italy: How Labour Market Policies can Foster Earnings Inequality." In Changing Inequalities and Societal Impacts in Rich Countries: Thirty Countries' Experiences, edited by B. Nolan, W. Salverda, D. Checchi, I. Marx, A. McKnight, I. G. Tóth, and H. G. van de Werfhorst, forthcoming. Oxford: Oxford University Press. Available at: http://checchi.economia.unimi.it/pdf/77.pdf.

Barbieri, P., and I. Bison. 2004. "Self-employment in Italy: Scaling the Class Barriers." In Self-employed Dynamics and Social Inequality: A Cross-national Study of Self-employment in Advanced Economies, edited by W. Muller and R. Arum, 121-173. Princeton, NJ: Princeton University Press.

Barbieri, P., and S. Scherer. 2009. "Labour Market Flexibilisation and its Consequences in Italy." European Sociological Review 25 (6): 677-692.

Barca, F. 2005. Italia frenata. Paradossi e lezioni della politica per lo sviluppo. Rome: Donzelli.

Beblo, M., and T. Knaus. 2001. "Measuring Income Inequality in Euroland." Review of Income and Wealth 47 (3): 301-320.

Beirlant, J., Y. Goegebeur, J. Teugels, and J. Segers. 2004. Statistics of Extremes: Theory and Applications. New York: Wiley.

Boeri, T., and P. Garibaldi. 2007. "Two Tier Reforms of Employment Protection: A Honeymoon Effect?" The Economic Journal 117 (521): 357-385.

Capasso, M., L. Alessi, M. Barigozzi, and G. Fagiolo. 2009. "On Approximating the Distributions of Goodness-of-fit Test Statistics based on the Empirical Distribution Function: The Case of Unknown Parameters." Advances in Complex Systems 12 (2): 157-167.

Cappellari, L., C. Dell'Aringa and M. Leonardi. 2012. "Temporary Employment, Job Flows and Productivity: A Tale of Two Reforms." The Economic Journal 122 (562): F188-F215.

Casadio, P. 2003. "Wage Formation in the Italian Private Sector after the 1992-93 Income Policy Agreements." In Institutions and Wage Formation in the New Europe, edited by G. Fagan, F. P. Mongelli and J. Morgan, 112-133. Cheltenham: Edward Elgar. 
Checchi, D. 2014. "Labour Market Reforms and Inequality in Italy." In The Politics of Social and Industrial Reforms: In Comparative Analysis of Italy and Japan, edited by H. Magara and S. Sacchi. Cheltenham: Edward Elgar. Available at: http://checchi.econo mia.unimi.it/pdf/un63.pdf.

Checchi, D., and L. Pagani. 2005. "The Effects of Unions on Wage Inequality. The Italian Case in the 1990s." Politica Economica 21 (1): 41-68.

Ciccarone, G., and G. Damioli. 2012. "Long-term Unemployment." EEO Review 2012, European Employment Observatory, Brussels. Available at: http://www.eu-employment -observatory.net/resources/reviews/Italy-LTU-July2012.pdf.

Clauset, A., C. R. Shalizi, and M. E. J. Newman. 2009. "Power-law Distributions in Empirical Data." SIAM Review 51 (4): 661-703.

Clauset, A., M. Young, and K. S. Gleditsch. 2007. "On the Frequency of Severe Terrorist Events." Journal of Conflict Resolution 51 (1): 58-88.

Codogno, L. 2009. "Two Italian Puzzles: Are Productivity Growth and Competitiveness Really so Depressed?" In Italy in EMU: The Challenges of Adjustment and Growth, edited by M. Buti, 87-116. London: Palgrave Macmillan.

Contini, B., L. Pacelli, R. Leombruni, and C. Villosio. 2008. "Wage Mobility and Dynamics in Italy in the 1990s." In The Structure of Wages: An International Comparison, edited by E. P. Lazear and K. L. Shaw, 373-400. Chicago: The University of Chicago Press.

Corsetti, G., and E. Mandrone. 2010. "Il lavoro: tra forma e sostanza. Una lettura dell'occupazione non standard in Italia." Economia \& Lavoro, no. 2: 71-97.

Cowell, F. A. 1980a. "Generalized Entropy and the Measurement of Distributional Change." European Economic Review 13 (1): 147-159.

Cowell, F. A. 1980b. "On the Structure of Additive Inequality Measures." The Review of Economic Studies 47 (3): 521-531.

Cowell, F. A. 2011. "Inequality among the Wealthy." Research Paper 150, Centre for the Analysis of Social Exclusion, London School of Economics, London. Available at: http:// sticerd.lse.ac.uk/dps/case/cp/CASEpaper150.pdf.

Cutuli, G. 2008. "Lavoro atipico e salari: una discriminazione nascosta nel mercato del lavoro italiano." Polis, no. 3: 403-422.

Cutuli, G., and R. Guetto. 2013. "Fixed-term Contracts, Economic Conjuncture, and Training Opportunities: A Comparative Analysis across European Labour Markets." European Sociological Review 29 (3): 616-629.

Dagum, C. 1997. "A New Approach to the Decomposition of the Gini Income Inequality Ratio." Empirical Economics 22 (4): 515-531.

D'Agostino, R. B. 1970. "Transformation to Normality of the Null Distribution of $g_{1}$." Biometrika 57 (3): 679-681.

Dell'Aringa, C., and L. Pagani. 2007. "Collective Bargaining and Wage Dispersion in Europe." British Journal of Industrial Relations 45 (1): 29-54.

Deville, J. C., and C. E. Särndal. 1992. "Calibration Estimators in Survey Sampling." Journal of the American Statistical Association 87 (418): 367-382.

Efron, B., and R. J. Tibshirani. 1993. An Introduction to the Bootstrap. New York: Chapman and Hall.

Faini, R., and A. Sapir. 2009. "An Obsolete Model? Growth and Specialisation in the Italian Economy." In Italy in EMU: The Challenges of Adjustment and Growth, edited by M. Buti, 1-36. London: Palgrave Macmillan.

Fiorio, C. V. 2011. "Understanding Italian Inequality Trends." Oxford Bulletin of Economics and Statistics 72 (2): 255-275.

Förster, M., D. K. Jesuit, and T. M. Smeeding. 2003. "Regional Poverty and Income Inequality in Central and Eastern Europe: Evidence from the Luxembourg Income Study." Research Paper 2003/65, World Institute for Development Economics Research, United Nations University, New York. Available at: http://www.wider.unu.edu/stc/repec/pdfs/ rp2003/dp2003-65.pdf.

Giammatteo, M. 2007. "The Bidimensional Decomposition of Inequality: A Nested Theil Approach.” Working Paper 466, Luxembourg Income Study, Luxembourg. Available at: http://www.lisdatacenter.org/wps/liswps/466.pdf. 
Giammatteo, M. 2009. “The Participation Labour Unemployment Survey: Methodology and Implementation." Paper presented at the first ITAlian COnference on Survey Methodology (ITACOSM09), Siena, Italy 2009.

Handcock, M. S., and M. Morris. 1998. "Relative Distribution Methods." Sociological Methodology 28 (1): 53-97.

Handcock, M. S., and M. Morris. 1999. Relative Distribution Methods in the Social Sciences. New York: Springer-Verlag Inc.

Hill, B. M. 1975. "A Simple General Approach to Inference about the Tail of a Distribution." The Annals of Statistics 3 (5): 1163-1174.

Inhaber, H., and S. Carroll. 1992. How Rich is Too Rich? Income and Wealth in America. New York: Praeger.

Keane, M. P., and E. S. Prasad. 2002. "Inequality, Transfer, and Growth: New Evidence from the Economic Transition in Poland." The Review of Economics and Statistics 84 (2): 324-341.

Kleiber, C., and S. Kotz. 2003. Statistical Size Distributions in Economics and Actuarial Sciences. New York: Wiley.

Lemieux, T. 2008. "The Changing Nature of Wage Inequality." Journal of Population Economics 21 (1): 21-48.

Lemieux, T., W. B. MacLeod, and D. Parent. 2007. "Performance Pay and Wage Inequality." The Quarterly Journal of Economics 124 (1): 1-49.

Lerman, R. I. 1999. "How do Income Sources Affect Income Inequality?" In Handbook of Income Inequality Measurement, edited by J. Silber, 341-362. Boston: Kluwer Academic Press.

Lerman, R. I., and S. Yitzhaki. 1985. "Income Inequalities Effects by Income Source: A New Approach and Applications to United States." Review of Economics and Statistics 67 (1): 151-156.

Lucidi, F. 2007. "Is There a Trade-off between Labour Flexibility and Productivity Growth? Some Evidence from Italian Firms." In Non-Standard Employment and Quality of Work: The Case of Italy, edited by T. Addabbo and G. Solinas, 261-285. Heidelberg: PhysicaVerlag.

Lucidi, F., and A. Kleinknecht. 2010. "Little Innovation, Many Jobs: An Econometric Analysis of the Italian Labour Productivity Crisis." Cambridge Journal of Economics 34 (3): 525-546.

Lucidi, F., and M. Raitano. 2009a. "Molto flessibili, poco sicuri: lavoro atipico e disuguaglianze nel mercato del lavoro italiano." Economia \& Lavoro, no. 2: 99-115.

Lucidi, F., and M. Raitano. 2009b. "Riforme del mercato del lavoro e disuguaglianze fra lavoratori permanenti e temporanei in Italia." In L'Italia delle disuguaglianze, edited by L. Cappellari, P. Naticchioni and S. Staffolani, 99-108. Rome: Carocci.

Lux, T. 1996. "The Stable Paretian Hypothesis and the Frequency of Large Returns: An Examination of Major German Stocks." Applied Financial Economics 6 (6): 463-475.

Mandrone, E., and M. Marocco. 2012. "Non Standard and Disguised Employment Relationship in Italy: An Economical and Juridical Approach." In Labour Economics: PLUS Empirical Studies, edited by E. Mandrone, 89-117. Cava de' Tirreni: Ediguida. Available at: http://sbnlo2.cilea.it/bw5ne2/opac.aspx?WEB=ISFL\&IDS=19149.

Mandrone, E., and D. Radicchia. 2005. PLUS Participation Labour Unemployment Survey. Indagine campionaria nazionale sulle caratteristiche e le aspettative degli individui sul lavoro. Soveria Mannelli: Rubbettino. Available at: http://bw5.cilea.it/bw5ne2/opac.aspx? $\mathrm{WEB}=\mathrm{ISFL} \& \mathrm{IDS}=5640$.

Mandrone, E., and D. Radicchia. 2012. Indagine Plus: il mondo del lavoro tra forma e sostanza. Soveria Mannelli: Rubbettino. Available at: http://sbnlo2.cilea.it/bw5ne2/opac.aspx? WEB=ISFL\&IDS=18957.

Morduch, J., and T. Sicular. 2002. "Rethinking Inequality Decomposition with Evidence from Rural China." The Economic Journal 112 (476): 93-106.

Morris, M., A. D. Bernhardt, and M. S. Handcock. 1994. "Economic Inequality: New Methods for New Trends." American Sociological Review 59 (2): 205-219.

Mussard, S. 2004. "The Bidimensional Decomposition of the Gini Ratio. A Case Study: Italy." Applied Economics Letters 11 (8): 503-505. 
Mussard, S. 2006. "Une réconciliation entre la décomposition en sous-groupes et la décomposition en sources de revenu de l'indice de Gini. La multi-décomposition de l'indicateur de Gini." Annales d'Économie et de Statistique 81: 169-193.

OECD. 2011. Divided We Stand: Why Inequality Keeps Rising. Paris: OECD Publishing.

OECD. 2012. "Inequality in Labour Income - What are its Drivers and How Can It be Reduced?" OECD Economics Department Policy Notes 8, Organisation for Economic Co-operation and Development, Paris. Available at: http://www.oecd.org/eco/public -finance/lessincomeinequalityandmoregrowth-aretheycompatible.htm.

Pareto, V. 1895. "La legge della domanda." Giornale degli Economisti 10: 59-68.

Pareto, V. 1896. "La courbe de la répartition de la richesse." Reprinted in OEeuvres complètes de Vilfredo Pareto, Tome 3: Écrits sur la courbe de la répartition de la richesse, edited by G. Busino, 1-15, 1965. Geneva: Librairie Droz.

Pareto, V. 1897a. Course d'Économie Politique. London: Macmillan.

Pareto, V. 1897b. "Aggiunta allo studio della curva delle entrate." Giornale degli Economisti 14: $15-26$.

Paul, S. 2004. "Income sources effects on inequality." Journal of Development Economics 73 (1): 435-451.

Picchio, M. 2006. "Wage Differentials and Temporary Jobs in Italy." Discussion paper 200633, Département des Sciences Economiques, Université catholique de Louvain. Available at: http://sites-final.uclouvain.be/econ/DP/IRES/2006-33.pdf.

Piketty, T., and E. Saez. 2003. "Income Inequality in the United States, 1913-98." The Quarterly Journal of Economics 118 (1): 1-39.

Piketty, T., and E. Saez. 2006. "The Evolution of Top Incomes: A Historical and International Perspective." The American Economic Review 96 (2): 200-205.

Podder, N. 1993. "The Disaggregation of the Gini Coefficient by Factor Components and its Applications to Australia." Review of Income and Wealth 39 (1): 51-61.

Pugliese, E. 2008. "Dalla disoccupazione di massa alle nuove precarietà." In L'economia della precarietà, edited by P. Leon and R. Realfonzo, 63-74. Rome: Manifestolibri.

Quintano, C., R. Castellano, and A. Regoli. 2006. "The Contribution of Income from Self-employment to Income Inequality. A Decomposition Analysis of Inequality Measures by Sources and Subgroups for Italy, 1998-2002." A Decomposition Analysis of Inequality Measures by Sources and Subgroups for Italy, Statistica \& Applicazioni 4 (2): 173-190.

Rani, U. 2008. "Impact of Changing Work Patterns on Income Inequality.” Discussion Paper 193, International Labour Organization, Geneva. Available at: http://www.ilo.org/inst/ publication/discussion-papers/WCMS_193166/lang-en/index.htm.

Schindler, M. 2009. "The Italian Labor Market: Recent Trends, Institutions, and Reform Options." Working Paper 09/47, International Monetary Fund, Washington. Available at: http://www.imf.org/external/pubs/ft/wp/2009/wp0947.pdf.

Shorrocks, A. F. 1982. "Inequality Decomposition by Factor Component." Econometrica 50 (1): 193-211.

Shorrocks, A. F. 1983. "The Impact of Income Components on the Distribution of Family Incomes." The Quarterly Journal of Economics 98 (2): 311-326.

Shorrocks, A. F. 1984. "Inequality Decomposition by Population Subgroups." Econometrica 52 (6): 1369-1385.

Stephens, M. A. 1986. "Tests Based on EDF Statistics.” In Goodness-of-Fit Techniques, edited by R. B. D'Agostino and M. A. Stephen, 97-193. New York: Marcel Dekker.

Stirati, A. 2008. "La flessibilità del mercato del lavoro e il mito del conflitto tra generazioni." In L'economia della precarietà, edited by P. Leon and R. Realfonzo, 181-191. Rome: Manifestolibri.

Theil, H. 1967. Economics and Information Theory. Amsterdam: North-Holland.

Torrini, R. 2005. "Cross-country Differences in Self-employment Rates: The Role of Institutions." Labour Economics 12 (5): 661-683.

Torrini, R. 2006. "Self-employment Incidence, Overall Income Inequality and Wage Compression." Paper prepared for the 29th General Conference of the International Association for Research in Income and Wealth, Joensuu, Finland, 20-26 August. Available at: http://www.iariw.org/papers/2006/torrini.pdf. 
Tronti, L. 2007. “The July Protocol and Economic Growth: The Chance Missed.” In Social Pacts, Employment and Growth, edited by N. Acocella and R. Leoni, 69-95. Heidelberg: Physica-Verlag.

Van Kerm, P. 2013. "Generalized Measures of Wage Differentials." Empirical Economics 45 (1): 465-482.

Voitchovsky, S. 2005. "Does the Profile of Income Inequality Matter for Economic Growth?: Distinguishing between the Effects of Inequality in Different Parts of the Income Distribution." Journal of Economic Growth 10 (3): 273-296.

Zenezini, M. 2004. "Il problema salariale in Italia." Economia e Lavoro 38 (2): 147-181.

\section{Appendix A: Derivation of the nested decomposition rule}

Consider a total distribution of income, $Y$, and a population of $n$ units (individuals or households) divided into $K$ mutually exclusive and exhaustive groups ${ }^{38}$ receiving income from $M$ different sources, $Y^{m}$, such that

$$
Y=\sum_{i=1}^{n} y_{i}=\sum_{k=1}^{K} \sum_{i=1}^{n_{k}} y_{i k}=\sum_{k=1}^{K} \sum_{i=1}^{n_{k}} \sum_{m=1}^{M} y_{i k}^{m}
$$

where $y_{i k}^{m}$ is the amount of $Y^{m}$ received by the unit $i$ of group $k \cdot{ }^{39}$ Given the Theil well-known formula

$$
T(Y)=\frac{1}{n} \sum_{i=1}^{n} \frac{y_{i}}{\mu} \ln \frac{y_{i}}{\mu}
$$

a nested decomposition rule can be derived through the following three simple steps (Giammatteo 2007).

1. The basic source-based decomposition of the Theil is

$$
T(Y)=\frac{1}{n} \sum_{i=1}^{n} \frac{y_{i}}{\mu} \ln \frac{y_{i}}{\mu}=\sum_{m=1}^{M}\left(\frac{1}{n} \sum_{i=1}^{n} \frac{y_{i}^{m}}{\mu} \ln \frac{y_{i}}{\mu}\right)=\sum_{m=1}^{M} T(m)
$$

where $y_{i}^{m}$ is the amount of $Y^{m}$ received by the unit $T(m)=\frac{1}{n} \sum_{i=1}^{n} \frac{y_{i}^{m}}{\mu} \ln \frac{y_{i}}{\mu}$ and is the generic
pseudo-Theil for the income source $m$. 2. The standard subgroups decomposition of the Theil index is given by

$$
T(Y)=\sum_{k=1}^{K} \pi_{k} s_{k} \ln \frac{\mu_{k}}{\mu}+\sum_{k=1}^{K} \pi_{k} s_{k}\left(\frac{1}{n_{k}} \sum_{i=1}^{n_{k}} \frac{y_{i k}}{\mu_{k}} \ln \frac{y_{i k}}{\mu_{k}}\right)=T b(Y)+T w(Y)
$$

where $\pi_{k} s_{k}=\frac{n_{k}}{\mu_{k}}$ is the income share of group $k$. Notice that the first term, $\operatorname{Tb}(Y)$, contributes nothing only if $s_{k}=1, \forall k$; in all other cases it will be strictly positive. The second term, $T w(Y)$, which corresponds to the weighed mean of the $K$ sub-indices $T_{k}=\frac{1}{n_{k}} \sum_{i=1}^{n_{k}} \frac{y_{i k}}{\mu_{k}} \ln \frac{y_{i k}}{\mu_{k}}$, is also never negative and reaches its minimum (zero) only in the case of equally distributed incomes inside each subgroup of the population.

3. By considering the following additivity in sub-means

$$
\mu_{k}=\sum_{m=1}^{M} \mu_{k}^{m}
$$


we are able to divide the between-group component of total inequality into $M$ source contributions as

$$
T b=\sum_{m=1}^{M}\left(\sum_{k=1}^{K} \frac{n_{k}}{n} \frac{\mu_{k}^{m}}{\mu} \ln \frac{\mu_{k}}{\mu}\right)=\sum_{m=1}^{M} T b(m)
$$

where $\frac{n_{k}}{n} \frac{\mu_{k}^{m}}{\mu}$ is the $m$ source share of total income for the subpopulation $T b(m)=\sum_{k=1}^{n} \frac{n_{k}}{n} \frac{\mu_{k}^{m}}{\mu} \ln \frac{\mu_{k}}{\mu}$. and is the pseudo-Theil index computed on the $K$ subgroup means. Following a similar procedure, but considering the individual income relations $y_{i k}=\sum_{m=1}^{M} y_{i k}^{m}$ instead of (A1), we can decompose the within-group component of the Theil index by income sources as

$$
T w=\sum_{m=1}^{M}\left[\sum_{k=1}^{K} \pi_{k} s_{k}\left(\frac{1}{n_{k}} \sum_{i=1}^{n k} \frac{y_{i k}^{m}}{\mu_{k}} \ln \frac{y_{i k}}{\mu_{k}}\right)\right]=\sum_{m=1}^{M} T w(m)
$$

where $T w(m)=\sum_{k=1}^{K} \pi_{k} s_{k} T_{k}(m)$ is a weighted sum of $K$ pseudo-Theil indices $T_{k}(m)=\frac{1}{n_{k}} \sum_{i=1}^{n k} \frac{y_{i k}^{\prime \prime}}{\mu_{k}} \ln \frac{y_{i k}}{\mu_{k}}$.

Expressions (A2) and (A3) allow us to derive the following subgroup-source nested decomposition of the Theil index

$$
T(Y)=T b+T w=\sum_{m=1}^{M} T b(m)+\sum_{m=1}^{M} T w(m)
$$

where $T b(m)$ and $T w(m)$ represent, respectively, the contribution to between- and within-group inequality coming from the $m$ income component.

\section{Appendix B: The Gini multi-decomposition}

In this appendix, we test the robustness of the results of our decomposition exercise by applying a multi-decomposition of the Gini index based on the technique proposed by Mussard (2004, 2006).

The Gini index multi-decomposition is a subgroup Gini decomposition in which both the within-group $\left(G_{w}\right)$ and the between-group $\left(G_{g b}\right)$ elements are further decomposed by income sources, i.e.

$$
G=\sum_{m=1}^{M}\left(G_{w}^{m}+G_{g b}^{m}\right)
$$

where $G_{w}^{m}$ and $G_{g b}^{m}$ are respectively the contributions of the $m$ th source to $G_{w}$ and $G_{g b} .{ }^{40}$

The advantage of the Gini multi-decomposition is similar in spirit to that used for the Theil index: instead of looking only at the 'margins' - either the contribution of source $m$ or the contribution of subgroup $k$ to the overall amount of inequality $G$ - the multi-decomposition provides the contribution of the $m$ th source of the within- and between-group inequalities that account for the global Gini index. In other words, unlike marginal decompositions, it is possible to appreciate the contribution of a particular source of a precise subgroup to the overall amount of inequality and estimate the contribution of a source to the between-group disparities. $^{41}$

The results stemming from application of this methodology to the PLUS data can be assessed by inspection of Table B1, whose structure is the same as in Table 4. The (standard) decomposition by income sources indicates that most of the inequality comes from selfemployment income, even if its contribution has been decreasing steadily over the years (from more than $65 \%$ in 2005 to around $50 \%$ in 2010). ${ }^{42}$ The multi-decomposition allows us to see that this source's contribution largely comes from within the rich group - it accounts 
on average for about $24 \%$ of total within-group inequality, although the between-group contribution is also quite large (more than $66 \%$ per year).

The marginal decomposition by population subgroups reveals that a large amount of inequality comes from between the two groups of rich and non-rich workers - on average, $63 \%$ of total inequality. As noted above, when looking at the multi-decomposition it appears that self-employment income contributed most to between-group disparities, while earnings from standard forms of work seem to have played more influence through within-group inequalities.

Needless to say, the results are as expected and adequately in line with those obtained using the nested Theil decomposition method.

Table B1. Standard and multi-decomposition of the Gini index by population subgroups and income sources. ${ }^{\mathrm{a}}$

\begin{tabular}{|c|c|c|c|c|c|c|c|c|c|}
\hline & \multicolumn{4}{|c|}{ Absolute values } & \multicolumn{4}{|c|}{ Percent values } & \multirow{2}{*}{$\begin{array}{c}\text { Subgroup } \\
\text { dec. }\end{array}$} \\
\hline & Standard & $\begin{array}{c}\text { Self- } \\
\text { employed }\end{array}$ & Atypical & $\begin{array}{l}\text { Gross } \\
\text { inc. }\end{array}$ & Standard & $\begin{array}{c}\text { Self- } \\
\text { employed }\end{array}$ & Atypical & $\begin{array}{l}\text { Gross } \\
\text { inc. }\end{array}$ & \\
\hline \multicolumn{10}{|l|}{2005} \\
\hline Non-rich ${ }^{\mathrm{b}}$ & 0.077 & 0.006 & -0.005 & 0.078 & 70.6 & 5.5 & -4.6 & 71.6 & - \\
\hline $\operatorname{Rich}^{\mathrm{c}}$ & -0.004 & 0.035 & 0.001 & 0.032 & -3.7 & 32.1 & 0.9 & 29.4 & - \\
\hline Within & 0.073 & 0.041 & -0.004 & 0.109 & 67.0 & 37.6 & -3.7 & 100.0 & 32.3 \\
\hline Between & 0.050 & 0.180 & -0.002 & 0.228 & 21.9 & 78.9 & -0.9 & 100.0 & 67.7 \\
\hline Source dec. & 0.123 & 0.221 & -0.006 & 0.337 & 36.4 & 65.4 & -1.7 & 100.0 & 100.0 \\
\hline \multicolumn{10}{|l|}{2006} \\
\hline Non-rich ${ }^{\mathrm{b}}$ & 0.082 & 0.008 & -0.007 & 0.083 & 74.5 & 7.3 & -6.4 & 75.5 & - \\
\hline $\operatorname{Rich}^{\mathrm{c}}$ & -0.004 & 0.030 & 0.001 & 0.027 & -3.6 & 27.3 & 0.9 & 24.5 & - \\
\hline Within & 0.078 & 0.038 & -0.006 & 0.110 & 70.9 & 34.5 & -5.5 & 100.0 & 34.1 \\
\hline Between & 0.071 & 0.149 & -0.007 & 0.213 & 33.3 & 70.0 & -3.3 & 100.0 & 65.9 \\
\hline Source dec. & 0.150 & 0.187 & -0.013 & 0.323 & 46.3 & 57.7 & -4.0 & 100.0 & 100.0 \\
\hline \multicolumn{10}{|l|}{2008} \\
\hline Non-rich ${ }^{\mathrm{b}}$ & 0.077 & 0.004 & -0.007 & 0.074 & 68.1 & 3.5 & -6.2 & 65.5 & - \\
\hline $\operatorname{Rich}^{\mathrm{c}}$ & -0.002 & 0.038 & 0.002 & 0.039 & -1.8 & 33.6 & 1.8 & 34.5 & - \\
\hline Within & 0.075 & 0.042 & -0.005 & 0.113 & 66.4 & 37.2 & -4.4 & 100.0 & 33.2 \\
\hline Between & 0.081 & 0.150 & -0.004 & 0.226 & 35.8 & 66.4 & -1.8 & 100.0 & 66.8 \\
\hline Source dec. & 0.155 & 0.192 & -0.009 & 0.339 & 45.9 & 56.7 & -2.5 & 100.0 & 100.0 \\
\hline \multicolumn{10}{|l|}{2010} \\
\hline Non-rich ${ }^{b}$ & 0.149 & 0.015 & -0.011 & 0.153 & 93.7 & 9.4 & -6.9 & 96.2 & - \\
\hline $\operatorname{Rich}^{\mathrm{c}}$ & 0.002 & 0.004 & 0.001 & 0.007 & 1.3 & 2.5 & 0.6 & 4.4 & - \\
\hline Within & 0.151 & 0.019 & -0.010 & 0.159 & 95.0 & 11.9 & -6.3 & 100.0 & 47.8 \\
\hline Between & 0.039 & 0.131 & 0.005 & 0.174 & 22.4 & 75.3 & 2.9 & 100.0 & 52.2 \\
\hline Source dec. & 0.190 & 0.150 & -0.006 & 0.334 & 56.8 & 44.9 & -1.7 & 100.0 & 100.0 \\
\hline
\end{tabular}

Source: authors' own calculations using the PLUS data.

${ }^{a}$ Figures might not add up because of rounding.

${ }^{\mathrm{b}}$ Includes individuals with income $<\hat{x}_{\min }^{*}$.

${ }^{\mathrm{c}}$ Includes individuals with income $\geq \hat{x}_{\min }^{*}$. 